Strategy for Earth Explorers in Global Earth Sciences

National Research Council, Washington, DC

Prepared for:

National Aeronautics and Space Adminustration, Washington, DC

1988

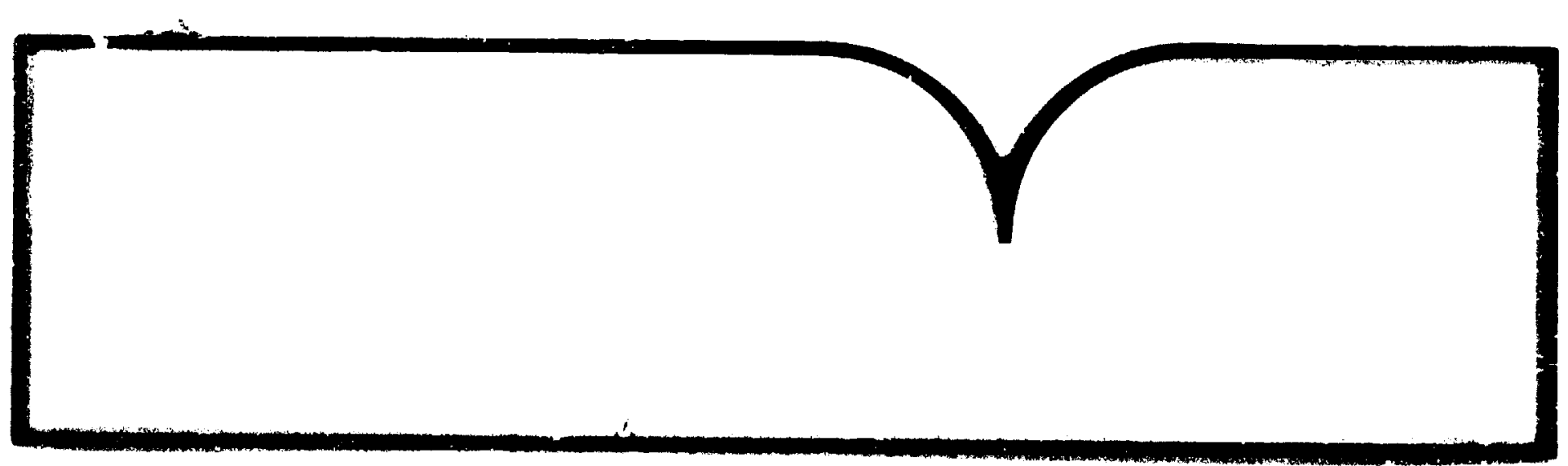





\title{
Strategy for Earth Explorers in Global Earth Sciences
}

\author{
Committec on Earth Sciences \\ Space Science Board \\ Commission on Physical Sciences, Mathematics, and Resources \\ National Research Council
}

NATIONAL ACADEMY PRESS

Washington, D.C.

1988 
NOTICE: The project that is the subject of this report was approved by the Governing Board of the National Research Council, whose members are drawn from the councils of the National Acaderay of Sciences, the National Academy of Engineering, and the Institute of Medicine. The members of the committee responsible for the report were chosen for their special competences and with regard for appropriate balance.

This report has been reviewed by a group other than the authors according to procedures approved by a Report Review Committee consisting of members of the National Academy of Sciences, the National Academy of Engineering, and the Institute of Medicine.

The National Academy of Sciences is i private, nonprofit, self-perpetuating society of distinguished scholars engaged in scientific and engineering research, dedicated to the furtherance of science and technology and to their use for the general welfare. Upon the authority of the charter granted to it by the Congress in 1863, the Academy has a mandate that requires it to advise the federal government on scientific and technical matters. Dr. Frank Press is president of the National Academy of Sciences.

The National Academy of Engineering was established in 1964, under the charter of the National Academy of Sciences, as a parallel organization of outstanding engineers. It is autonomous in its administration and in the selection of its members, sharing with the National Academy of Sciences the responsibility for advising the federal government. The National Academy of Engineering also sponsors engineering programs aimed at meeting national ne:ds, encourages education and research, and recognizes the superior achievements of engineers. Dr. Robert $M$. White is president of the National Academy of Engineering.

The Institute of Medicine was established in 1970 by the National Academy of Scier.ces to secure the serricen of eminent members of appropriate professions in the examination of policy matters pertaining to the health of the public. The Institute acts under the responsibility given to the National Academy of Sciences by its congressional charter to be an adviser to the federal government and, upon its own initiative, to identify issues of medical care, research, and education. Dr. Samuel $O$. Thier is president of the Institute of Medicine.

The National Research Council was organized by the National Academy of Sciences in 1916 to associate the broad community of science and technology with the Academy's purposes of furthering knowledge and advising the federal government. Functioning in accordance with general policies detcrmined by the Academy, the Council has become the principal operating agency of both the National Academy of Sciences and the Nationa! Academy of Engineering in providing services to the government, the public, and the gcientific and engineering communities. The Council is administered juintly by both Acader ies and the Institute of Medicine. Dr. Frank Press and Dr. Robert M. White are chairman and vice chairman, respectively, of the National Research Council.

Support fur this project was provided by Contract NASW 3482 between the National Academy of Sciences and the National Aeronautics and Space Administration.

Space Science Board

2101 Constitution Ave., N.W.

Washington, D.C. 20418

Printed in the United States of America 


\section{COMMITTEE ON EARTH SCIENCES}

Byron Tapley, University of Texas, Chairman John Adams, University of $W$ shington

George Backus, University of California at San Diego

Robert Dickinson, National Center for Atmospheric Research

John Dution, Pennsylvania State University

Dennis Hartmann, University of Washington

Marcia McNult, Massachusetts Institute of Technology

Gerald North, Texas A\&M University

Williain Schlesinger, Duke University

Raymond Smith, University of California at Santa Barbara

Robert Stewart, Scripps Institution of Oceanography

Alan Thorndike, University of Puget Sound

Charles Yentsch, Bigelow Laboratory of Oceanic Science

Paul Zinke, University of California at Berkeley 


\section{SPACE SCIENCE BOARD}

Louis Lanzerotti, Bell Laboratories, Chairman

Philip Abelson, American Association for the Advancement of Science

Larry Esposito, University of Colorado

Jonathan Grindlay, Harvard Observatory

Andrew Ingersoll, California Institute of Technology

John Leibacher, National Solar Observatory

Michael Mendillo, Boston University

Roger Phillips, Southern Methodist University

David Raup, University of Chicago

Joseph Reynolds, Louisiana State University

George Siscoe, University of California at Los Angeles

L. Dennis Smith, University of California at Irvine

Byron Tapley, University of Texas 


\section{COMMISSION ON PHYSICAL SCIENCES, MATHEMATICS, AND RESOURCES}

Norman Hackerman, Robert. A. Welch Foundation, Chairman

George F. Carrier, Harvard University

Herbert D. Doan, The Dow Chemical Company (retired)

Peter S. Eagleson, Massachusetts Institute of Technology

Dean E. Eastman, IBM, T. J. Watson Research Center

Marye Anne Fox, University of Texas

Gerhart Friedlander, Brookhaven National Laboratory

Lawrence W. Funkhouser, Chevron Corporation (retired)

Phillip A. Griffiths, Duke University

Christopher F. McKee, University of California at Berkeley

Jack E. Oliver, Cornell University

Jeremiah P. Ostriker, Princeton University Observatory

Frank L. Parker, Vanderbilt University

Denis J. Prager, MacArther Foundation

David M. Raup, University of Chicago

Richard J. Reed, University of Washington

Roy F. Schwitters, Harvard Univer sity

Robert E. Sievers, University of Colorado

Leon T. Silver, California Institute of Technology

Larry L. Smarr, National Center for Supercomputing Applications

Edward C. Stone, California Institute of Technology

Karl K. Turekian, Yale University

Raphael G. Kasper, Executive Director

Myron F. Uman, Associate Executive Director 


\section{Preface}

In March 1987 NASA's Space and Earth Science Advisory Committee (SESAC) formally identified the need for "a strategy for incorporating small, flexible missions, particularly those with rapid response times, in the overall program for the earth sciences." The SESAC noted that although small-mission science strategies had been prepared by the Space Science Board's (SSB) Committee on Solar and Space Physics and Committee on Space Astronomy and Astrophysics, and by NASA's Solar System Exploration Committee for their respertive disciplines, a comparably detailed scientific strategy had not bee developed for NASA's earth science program. Following the SESAC recommendation, NASA's Office of Space Science and Applications asked the NRC's Space Science Board to conduct a study that would evaluate the small missions concept for earth science research.

The SSB's Committee on Earth Sciences (CES) discussed the need for writing such a report at its 1987 spring meeting. The committee proposed that the report determine the scientific rationale for establishing a line of "Explorer-class" missions in the earth sciences, and address institutional and programmatic issues in devising a comprehensive strategy.

The Space Science Board authorized the writing of this report on May 1, 1987. In approving the study, the board noted it had previously recommended that NASA not dilute the existing Explorer

\section{Preceding page blank}


program with the addition of more disciplines, unless funding for that program were substantially increased. As a result, the SSB directed the committee to frame its arguments to support either a separate small mission line for the earth sciences or a greatly expanded Explorer line. With this caveat, the CES was charged with the following tasks:

1. Assess the need for establishing a line of small missions in the earth sciences to achieve the goals and objectives outlined in the previous CES report, A Strategy for Earth Science from Space, Parts I and II, and review other relevant reports as appropriate.

2. Provide examples of potential missions.

3. Define the role and scope of such a mission line, including the levels of funding, launch rate, mission capabilities, and relation to other earth science missions and programs.

4. Address related issues such as the impact on the earth science community and university programs, and federal interagency and international cooperation.

The CES began gathering information in October 1987 and developed the report during the winter/spring of 1988. The committee consulted numerous scientific and technical colleagues in addition to a variety of reports and journals. Appendix A lists those references.

Before the committee completed this study, the Office of Space Science and Applications (OSSA) published its first 5-year program strategy. The OSSA strategy for the Earth Science and Applications Division included plans to establish a program for a series of small missions in the earth sciences, beginning in fiscal year 1990, similar to the one proposed in our report. Although the committee is encouraged by this important first step, we are well aware of the many hurdles that remain in bringing such a concept to fruition. The committee consequently forwards this report with the express intent of endorsing this preliminary action by NASA and to assist the agency in the successful realization of an effective-and permanent-Earth Explorer mission line.

Byron D. Tapley, Chairman

Committee on Earth Sciences 


\section{Contents}

1 EXECUTIVE SUMMARY

Introduction, 1

Recommendations, 4

2 EARTH SCIENCE FROM SPACE

Introduction, 7

Scientific Strategy for the Earth Sciences, 8

The Need for Earth Explorer Missions in Global Earth

Sciences, 11

3 THE EARTH EXPLORER PROGRAM

15

Introduction, 15

Past Missions, 16

Prospective Missions, 30

4 STRATEGY FOR AN EFFECTIVE PROGRAM

APPENDIXES

A REFERENCES

49

B REPRESEN'TATIVE EARTH EXPLORER PROGRAM 


\section{1 \\ Executive Summary}

\section{INTRODUCTION}

The goal of the current NASA Earth System Science initiative is to obtain a comprehensive scientific understanding of the Earth as an integrated, dy namic system. To achieve this goal, the components of the Earth's system must be identified, their functions defined, and their evolution over all time scales understood. The need to predict changes resulting from both natural and anthropogenic causes, during periods as short as a decade and as long as a century, provides a formidable challenge. A successful program for identifying, aralyzing, and predicting global change will require measuring a number of bisic physical, chemical, and biological components of the Earth's system on a global scale with adequate temporal and geographical sampling.

The centerpiece of the Earth System Science initiative will be a set. of instruments carried on polar-orbiting platforms under the Earth Observing System (Eos) program. The program involves collaboration by NASA witn other national and international agencies. The Eos instruments will address many of the recommendations for global measuiements of important environmental variables as outlined in a previous Committee on Earih Sciences (CES) repcrt, $A$ 
Strategy for Earth Science from Space, Parts I and II.* 'The measurements are expected to contribute significantly to the International Geosphere-Biosphere Program (IGBP) and NASA's Mission to Planet Earth initiative, and they will stimulate earth cystem science research during the next decade.

The comuittee endorses the Earth System Science initiative. However, in examining the current needs of the earth sciences in light of the former CES recommendations and in attempting to project current trends into the next decade, the cornmittee finds several issues that require prompt attention. These concerns focus on the adequacy of the proposed observations and on the overall vitality-in terms of innovation, training, and programmatic Hexibility-in the earth sciences community. Although a wide rangu of measurements can be taken by the planned Eos platforms, a number of other observations identified in the previous CES strategy and in other $\mathrm{Na}$ tional Research Cuuncil and federal agency reports cannot be made from the platforms because of special orbit or sensor requirenents. These include high-resolution measurements of the g'obal gravity field and its time variation; active microwave measurements of global precipitation throughout the diurnal cycle, which requires a nonsynchronous orbit; and repeated observations of the Earth's magnetic field with sufficient accuracy to aliow the characterization of decadal variations, which requires a magnetically "clean" sateilite. The altitude and inclination of the polar-orbiting Eos platforms, together with their sun-synchronous orbits, will preclude such measurements, as well as a number of others discussed in the body of this report.

Plans tc obtain some of these data sets are included in proposed, but unscheduled, missions such as the Geopntential Resear-h Mission, the Tropical Rainfall Measurement Mission, and the Magnetic Field Explorer. In cortrast to the Explorer program for astronomy and astrophysics and solar and space physics, howcver, NASA dues not currently have the appropriate programmatic structure for implementing these and other small and moderate-size earth science missions.

Recent events have underscored our inability to inaintain critical time series measurements. A gap in ocean color observations, important to the area of biological oceanography for the study of glcbal biogeochemical cycles and the prediction of long-term climatir changes,

*A complete list of references used in the preparation of this report is included in Appendix A. 
has already occurred with the termination of the Coastal Zone Color Scanner measurements on Nimbus 7 in 1986. Global stratospheric total ozone measurements with high spatial resolution, instrumental in monitoring the recurring phenomenon of stratospheric ozone depletion above the Antarctic, will soon become unavailable because no firm plans have been made fnr a follow-on mission to the Nimbus 7 Total Ozone $N_{1}$,ping Spectrometer. A similar gap in the collection of data on the Earth's radiative exchanges of energy, indispensable to a better understanding of climatic processes and the "Breenhouse effect," is expected to occur at the end of the current Earth Radiation Budget Experiment.

Although all of these instruments are planned for the Eos platforms, the potential lapse of such measurements during the first half of the $199 \mathrm{Gs}$ will be extremely disruptive to global change research programs. Those programs rely on uninterrupted data flows to improve quantitative models of the earth system for identifying and simulating environmental trends. In addition, NASA's ability to make specialized measurements of new or rapidly changing phenomens, such as ocean pollution and greenhouse gases, continues to be severely limited.

With the growing capabilities of other nations to perform earth observations from satellites, it is also important for NASA to maintain the flexibility for responding in a timely manner to opportunities for international cooperation. Such a capability will be needed for a comprehensive program in earth system science and, in particular, to fulfill the requirements of the IGBP and Mission to Planet Earth initiatives.

The vitality of the space component of the earth sciences was established in part through a series of inexpensive Explorer missions from the late 1950s into t'se 1970s. Indeed, the Explorer program assured progress in many earth science disciplines throughout the early history of space exploration. It promoted frequent access to space, supported missions of a specific or unique nature, provided a quick and flexible reaction capability, bridged the programmatic gap between sounding rockets and major missions, presented more effective and divarse opportunities for international cooperation, and gieatly enhanced the educational and training programs at our universities. Unfortunately, with the exception of research in solar-terrestrial processes, access to the Explorer program enjoyed by the earth science community during the first two decades of the space age was lost by the early 1980s. Moreover, the ability to conduct small and 
moderate-size missions outside that program has been severely circumscribed as a greater proportion of NASA's earth science budget has been allocated to larger aud more complex missions.

\section{RECOMMENDATIONS}

An Earth Explorer program can open new vistas in the ea-th sciences, encourage innovation, and solve critical scientific problems. Specific missions must be rigorously shaped by the demands and opportunities of high-quality science and must complement the Earth Observing System and the Mission to Plaret Earth. It is therefore essential that the program follow a comprehensive strategy for accomplishing these goals.

The Committee on Earth Sciences recommends that a new Earth Explorer mission series be funded at a level ticat would allow the construciion of two small missions per year, or one moderate mission every 9 years. Announcements of opportunity for such missions should be divided according to two separate solicitations, one for missions and instrumenis costing less than $\$ 90$ million and one for missions in the $\$ 90$ million to $\$ 150$ million range. The Earti Explorer series should be established es a level-of-effort program similar to the existing Explorer line, but managed nntirely by NASA's Earth Science and Applications Division. Maintrining independent control over the program will help ensure that it remains responsive to the needs of the earth sciences community and will prevent the further dilution of an already oversulscribed Explorer program for astronomy and astrophysics, and solar and space physics. The level of funding should be adequate to fly a continuous series of missions at an average rate of approximately one per year.

The traditional strength of the existing NASA Explorer line has been easy, frequent, and inexpensive access to space. The racommendations that follow are designed to return similar opportunities to the earth sciences.

1. Each Earth Explorer mission should be sharply focused on significant scientific issues. A mission should explore important scientific issues or fill in gaps that may arise in the collection of longterm data sets. The program could also provide the collateral benefit of advancing technology development in achieving its objectives. In any case, the missions should be justified by their own scientific merit. The Earth Explorers should not be used for the engineering 
development a.d flight testing $c^{s}$ instruments for large missions or platfr rms.

2. Proçammatic continuity and flexibility must be maintained. In order for the recommended program to have a significant impact on the earth sciences, it must be started with a clear eipectation of maintaining uninterrupted continuity. The program should also be designed for flexibility, both in choosing the most important scientific questions to address and in allowing for reasonably wide variations in the scale of the missions. Rapid response times are necessary to react in a timely manner to sudden changes in our environment, or to take advantage of opportunities to collaborate with other agencies or nations.

3. Costs must be rigorously controlled in all phases of the program. The key to the success of the Earth Explorer program will be to obtain the maximum scientifir value per dollar expended. The spiraling corts of instruments for observations from space can be controlled by sharply focusing the scientific objectives, by assigning principal investigators the prime res contro:, and by carefully assessing the tradeoff between reliability and multiple copies of instruments. Standard satellite buses and launch rehicles should be used wienever this is both scientifically and ecconomically advantageous.

4. Given the emphasis on strongly focused missions, the data transmi ssion and processing activities are likely to be elat:vely nodest. Nevertheless, strict schedules and reliability requirements must be met, and the data should be made availaúle as ouickly as fossible to sci ntific archives or to ope: networks in scient, fic formats. Careful planning and experimentation with the integration over networts of data from diverse sources will be essential.

5. A significant fraction of the total costs for each mission should be allocated to dnta analysis, interpretation, and reiated theoretical modeling work. Because the scie tific objectives for any mission are achieved only after the daia have bern distributed and thoroughly analyzed, adcquate funding for this purpose is fundamental to the missiun's success. The committee strongly recommends that the approprinte resource levels be silocate? to the mission operations and data analyeis budget to support such activities.

6. A basic goal of the Earth Exnlo.er program must be to speed up the conversion of concepts inio satcllite mission. and of raw data into scientific results. The time scales of the program must be designed to attract leading scientists and talented students, and to avoid the 
mounting costs of protracted space projects. Therefore it is essential that the missions be launched within 2 to 3 years of acceptance of engineering design for the smallest missions, and 3 to 4 years for the moderate-size ones.

7. The Earth Explorer program must develop a selection process that encourages the best ideas and does not require inordinate investments in engineering design during the initial proposal phase. To achieve this objective the selection process should proceed in two phases. In the first phase, proposals should be requested that emphasize the scientific issues and the instrument concepts, with only a limited discussion of engineering issues. In the second phase, only the most promising concepts should be chosen for further development and preliminary instrument design in order to compete in a further selection process. This approach will minimize the total community investment in pre; aring proposals, and will make it attractive for scientists with good ideas but limited resources to compete in the preliminary phase of Earti Explorer selection. The overselection of missions or instruments should be assiduously avoided.

8. Interagency and internationai collaberation must be optimized. Collaboration with other agencies and nations fosters the development of a stronger space science program at reduced cost to NASA. Every opportunity for cooperation in utilizing and financing Earth Explorer missions should be consiùe:ed.

The committee believes that the proposed Earth Explorer program provides a substantial opportunity for progress in the earth sciences, both through independent missions and through missions designed to complement the large-scale platforms and international research programs that represent important national commitments. The strategy presented in this report is intended to help ensure the sinccess of the Earth Explorer program as a vital stimulant to the study of our planet. 
Earth Science from Space

\section{INTRODUCTION}

The U.S. space program began with the launch of an earth science mission in February 1958. Explorer 1 carried a Geiger counter into space and discovered the Van Allen radiation belts. Two months later the 4-kg Vanguard I provided new information about the shape of the Earth. This improved geodesy suggested convection currents in the Earth's mantle and was later incorporated in the theory of plate tectonics. The following year, Explorer 6 transmitted the first pictures of clouds taken from space. By 1963, nineteen Explorers, as well as many satellites bearing other names, had been launched. More than half of the early Explorer missions ware devoted to Earth observation, the others to measuring the solar wind and other extraterrestrial studies. Only five of the first nineteen Explorers exceeded $50 \mathrm{~kg}$ in total weight.

From these beginnings, a powerful spaceborne capability has grown for observing the Earth's gravity and magnetic fields, its atmosphere, land surface, and oceans. A wide variety of imaging systems has been developed, ranging from the visible to the microwave portions of the spectrum. Microwave altimeters have significantly improved our knowledge of the Earth's gravity field over the oceans and provided new insights into the structure and dynumic mechanisms 
of the ocean floor. Visible and near-infared imagery is essential for weather forecasting, and the same data have opened up new methods for the study of ocean processes and the estimation of living marine resources. Images of the land surface obtained from space have revealed detailed aspects of surface composition and geological features. Precise measurements of the distances between points thousands of kilometers apart are now possible using satellite laser ranging and radio interferometry. The opportunity is thus at hand to map the exposed surface of the continents at a resolution sufficient to define their nature and monitor their evolution, and to measure directly the relative motions of the Earth's tectonic plates on time scales of a few years.

Infrared and microwave satellite sensors are now used routinely to deduce vertical temperature profiles throughout the global atmosphere. Techniques have also been developed for measuring from space the concentrations of many important trace gases in the atmosphere and their variations with altitude. It is now possible to make precise measurements of surface elevation of the oceans, land, and ice masses from Earth orbit. The Earth's gravitational and magnetic fields can be determined for scales that range from global down to wavelengths comparable to the spacecraft altitude. Wind velocity at the surface of the ocean can be inferred from measurements of scattered radiation. The ability to measure sea surface elevation, wind stress over the ocean, and marine gravity will produce data that are essential to drive and to test computer models of the circulation of the world's ocean. Improvements in ocean models are needed to understand the poleward transport of heat, the distribution of sediments, and the exchange of gases between the ocean and atmosphere. In conjunction with space-based observations of the temperature and color, these measurements will also lead to better understanding of biological productivity, which in many cases is limited by the upwelling of nutrients from the deep ocean to the surface.

\section{SCIENTIFIC STRATEGY FOR THE EARTH SCIENCES}

The classical disciplines of geology, geophysics, meteorology, oceanography, biology, and chemistry are becoming increasingly integrated within the earth sciences. For example, the processes that maintain stratospheric ozone levels involve radiative transfer, aerosol physics, photochemistry, and atmospheric dynamics, and are affected by human production of certain synthetic substancrs. Significantly 
reduced ozone levels would affect biological communities both on land and in the ocean by allowing more ultraviolet radiation to reach Earth's surface.

Observations of the global climate changes that are taking place as a result of fossil fuel burning and other industrial activities provide another example of this integration. The climatic changes resulting from human activities over the next 100 years may be larger than any naturally occurring changes the Earth has experienced over the last million years or more, depending on the rate of increase of greenhouse gases. This rate of increase will be controlled by complex interactions between socioeconomic forces, geological production of carbon dioxide, and uptake of carbon dioxide and other industrial gases by geochemical and biological processes. In an age when human activities are changing the global environment at an increasingly rapid pace, a strong interaction between scientific discoveries about the Earth and the evolution of public policy is very important.

In addition to contributing to an increasing awareness of the close ties between the subdisciplines within earth sciences, space observations have provided humanity with a global perspective of the Earth as a self-contained physical, chemical, and biological system. Phenomena once believed to be local, such as the cyclical El Niño warmwater current in the eastern Pacific Ocean, are now known to be parts of patterns developing on a global scale.

One response to these changes has been the evolution of a new interdisciplinary approach cailed earth system science, which investigates the connections among components in the system. The classical method of isolating individual components for detailed analysis will remain vital, but cannot address the complex interactions among the many components that make up the Earth. As this revolution has spread through the earth sciences community, plans have evolved to study our planet from a global perspective. The First Global Atmospheric Research Program Experiment in 1979 was a successful initial attempt to characterize the atmosphere with greatly enhanced measurement cepabilities from ships, buoys, and satellites.

Today, the global emphasis is apparent in a number of studies, such as the International Lithosphere Program, the Global Tropospheric Chemistry Program, the Joint Global Ocean Flux Study, and the World Climate Research Prograin. The latter includes under its auspices the Tropical Oceans Global Atmosphere Program, the World Ocean Circulaticn Experiment, the International Satellite Cloud Climatology Project, and the International Satellite Land 
Surface Climatology Project. All of these research programs rely extensively on spacecraft measurements.

Preparations are now being made by a special committee of the International Council of Scientific Unions (ICSU) to initiate the most ambitious global study of all, the International Geosphere-Biosphere Program (IGBP). The objective of this program, as set forth by the ICSU General Assembly, is "to describe and understand the physical, chemical and biological processes that regulate the total Earth system, the unique environment that it provides for life, the changes that are occurring in this system and the manner in which they are influenced by human actions." The IGBP will take at least a decade to begin answering these questions and will require the cooperation of practically all countries to achieve success. Again, the principal tools needed to carry out this massive study will be a broad array of research and operational spacecraft in a variety of orbits and altitudes, as well as sophisticated data management capabilities to handle the vast quantities of scientific information.

Over the past few years a number of National Research Council and federal agency reports have examined the scientific and programmatic issues of earth system science. The Committee on Earth Sciences (CES) published A Strategy for Earth Science from Space in two parts, the first dealing with the solid earth and oceans (1982) and the second regarding the atmosphere and interactions with the solid earth, oceans, and biota (1985). The stated goals were as follows:

- to determine the composition, structure, and dynamics of the solid planet, its oceans and atmosphere, and the surrounding envelope of charged particles and fields;

- to characterize the systems oi living organisms and their interactions with their environment;

- to understand the processes by which the Earth formed as a planet and evolved to its present state;

- tc determine the atmospheric distributions and cycles of mass, energy, momentum, water vapor, and chemical constituents important to the climate and to the maintenance of life;

- to understand the physical and chemical dynamics of the atmosphere and its intera tions with the land, ice caps, oceans, and biota; and

- to understand the evolution of the atmosphere to its present state and to predict its future evolution on time scales of less than 100 years, including the effects of anthropogenic and natural perturbations. 
The CES strategy's goals and related scientific objectives figured prominently in the writing of subsequent reports, including two of the most recent ones in the globas carth sciences, Mission to Planet Earth and Earth System Science: A Frogram for Global Change, both published in 1988. Mission to Planet Earth is part of the Space Science Board study, Space Science in the Twenty-first Century. It takes the broadest perspective by considering the scientific objectives for the systematic study of the planet from its center to the outer reaches of the atmosphere. In order to address this comprehensive scope of scientific research, Mission to Planet Earth calls for a satellite-based observing system composed of five geostationary satellites, a set of two to six polar-orbiting platforms, and a series of special missions that require other orbits.

The other report, Earth System Science: A Program for Global Change, by NASA's Earth System Science Committee (ESSC), lays out a global strategy that U.S. agencies should follow to advance earth science research during the coming decades. The report's objective "to obtain a scientific understanding of the entire Earth system on a global scale by describing how its component parts and their interactions have evolved, how they function, and how they may be expected to evolve on all time scales," closely parallels the goals of the Mizsion to Planet Earth and the IGBP. The report also emphasizes the importance of maintaining a diverse space program and developing new instruments and techniques. Toward this end the ESSC recommends the establishment of two new initiatives by NASA: the Earth Observing System (Eos) polar-orbiting platforms and a complementary Earth System Explorer series of research missions.

\section{THE NEED FOR EARTH EXPLORER MISSIONS IN GLOBAL EARTH SCIENCES}

The centerpiece of the earth science program that NASA has proposed for the mid-1990s on is the Earth Observing System. Eos will consist of several major satellite observatories in polar orbits. By carrying many sensors, each observatory will combine the furctions now performed by a number of separate satellites. This integrated approach is expected to strengthen interdisciplinary research and international cooperation in the earth sciences.

Not all earth science objectives, however, can be achieved with instruments on the Eos observatories. Some missions require unique 
orbits or for other reasons do not fit into the Eos configuration. Examples that are discussed later in this report are the measicements that could be made by the proposed Geopotential Research Mission, the Tropical Rainfall Mission, the Magnetic Field Explorer, and a number of other very small missions or instruments. They necessitate additional flexibility in the space program to provide a wider variety of access to space. Although these types of missions have been endorsed scientifically and programmatically in previous reports, they have not been implemented.

The past successes of NASA's earth science program were founded on a broad spectrum of opportunities for research. Aircraft, balloons, shuttle flights, and small, modest satellite missions have all played important roles in complementing the data acquired by larger observatories. In recent years, the small and moderate-size earth science missions have nearly disappeared from the space programa dramatic reversal from the 1960 s, when the Explorer series was launching about four satellites a year, many devoted to earth science missions. The current NASA policy is to restrict proposals submitted to the existing Explorer program to the "traditional" Explorer fields of space physics and astronomy. Without the availability of a programmatic structure in which to initiate small and roderate-size missions the opportunities for earth science payloads have become severely restricted. This situation will continue into the Eos era unless corrective action is taken.

There are several advantages to small missions. They present a greater variety of access to space. They provide vehicles for incremental testing of technology and scientific ideas. And they typically involve less concept-to-launch time, less system integration, and less engineering overhead than large missions.

The rapid appearance of the Antarctic ozone hole in the late 1970 s has demonstrated the need for rapid responses to emerging concerns about the global environmental changes that are taking place. In the case of the Antarctic ozone depletion it was fortunate that an appropriate instrument was available to observe the phenomenon. This wes true only because of the unexpectedly long useful life of the Total Ozone Mapping Spectrometer (TOMS) instrument on the Nimbus 7 satellite. Yet a gap in these essential ozone measurements will occur unless immediate steps are taken to

Furthermore, with the growing capabilities of other nations in 
Earth observations, it is important that NASA maintain the flexibility to respond in a timely way to opportunities for international cooperation. The capacity to react to such opportunities is mandatory for a comprehensive program in the earth sciences and, in particular, to satisfy the requirements of the Mission to Planet Earth and the IGBP.

It is not clear that economies of scale necessarily favor large missions. For several instruments to share the same power, communications, and other utilities on a common platform appears sensible, but one adverse effect is to make the investment in these platforms very large. With large investments comes a need for designs that minimize the risk of failure, which further increases the costs. But with smaller missions, the risks associated with a failure are more modest, and the cost/risk spiral can be avoided.

The 1985 CES strategy stated that "the present frequency and mix of space flights are not adequate to maintain a vigorous, productive program in earth sciences." The Space Science Board's Committee on Space Astronomy and Astrophysics expressed a similar concern the following year in its report, The Explorer Program for As. tronomy and Astrophysice: "Small (initially) high-risk experiments may have been crowded from the market of ali space opportunities. Considerable improvement would follow naturally from a greater frequency of flight opportunities."

The U.S. space science program has benefited from the combined efforts of scientists in government agencies, in industry, and in university laboratories. The Explorer program has been of particular importance to space research conducted at universities. It has provided frequent opportunities for fundamental work at the forefront of earth and space science. Because of the comparatively short development and flight cycles of Explorer missions, students have been able to participate in all phases, from conceptual design to development, implementation, and scientific interpretation of data from individual space missions. Involvement with several phases of the full mission contributes to the student's development, leading, in the long run, to a pool of trained scientists and engineers for the space program. The lead time for most space missions has grown to at least 10 years from concept to launch. Yet graduation, promotion, and tenure within a university require productivity early in a career, making such long delays professionally unacceptable.

In the earth sciences, lack of access to space is now acutely and widely felt. It may lead to the discouragement of young scientists, 
the inability to attract the most creative students to the discipline, and the eventual failure of the nation to produce future generations of skilled space scientists and -ngineers.

A related effect of the long-lead, big-science structure is the boom-and-bust cycle it promotes in individual disciplines. The excitement of discovery that accompanies a successful major mission may be followed by years of waiting for the logical follow-on mission. A strategy that provides for frequent access to space, and that does not rely on big missions to the total exclusion of smail ones, will be much more effective and productive.

The need for frequent, low- and moderate-cost space experiments in the earth sciences is undeniable. The committee therefore recommends that NASA create a separate Earth Explorer line within the Earth Science and Applications Division ludget, beginning in fiscal year 1990. In the chapters that follow, the committee looks at past and prospective Explorer-class missions in the earth sciences and proposes a strategy for an effective program. 


\section{The Earth Explorer Program}

\section{INTRODUCTION}

The Earth Observing System (Eos) will be the centerpiece of the global program for observing the Earth, as discussed in the previous chapter. The system, comprising three to six large polar-orbiting platforms, will carry an elaborate suite of coordinated instruments, feeding data to an extensive network of sophisticated data processing and distribution systems. There is, however, a critical need for many global measurements of the atrnosphere, solid earth, and oceans that cannot be made either effectively or at all by Eos, but that could be accomplished by an Earth Explorer series of missions. The Earth Explorer program would provide access to space for low-cost spacecraft that require different orbital altitudes or inclinations from those previded by the proposed polar and geosynchronous platforms. In addition, the program would (1) provide the capability to respond rapidly and flexibly to evolving environmentai problems, or to new scientific or technological developments; (2) preserve continuity in the monitoring of important phenomena with variations on rapid or unknown timescales; and (3) foster opporturities for sharing ccsts with other space agencies. 


\section{PAST MISSIONS}

The earliest Explorer missions opened up entirely new, exciting fields in the earth sciences while bringing the nation to the forefront of space science. Of the Explorer spacecraft built and launched in the past 30 years, 44 out of 78 were devoted primarily to earth science objectives (see Tible 3.1). Significant accomplishments from these missions have inzluded the following:

- taking of the first pictures o: the Earth and its atmosphere, a capability that has subsequently vastly expanded our understanciing of weather systems, the biology and geography of the Earth's surface, and geological processes;

- determination of the inhomogeneous distribution of mass in the Earth;

- measurement of the censity and composition of the upper atmosphere and ionosphere;

- measurement of incoming solar radiation at the top of the aimosphere; and

- discovery of the Van Allen radiation belts.

The current lack of Explorer satellites devoted to earth science measurements in no way reflects an absence of outstanding candidates for such a class of missions. There are many examples of inexpensive, specialized, and extremely successful satellites from the past few decades that demonstrate the kind of science that may be jeopardized in the future unless an Earth Explorer line is established. For many of these satellites, the requirements for altitude, inclination, or ground tracks were so specific as to preclude flight on a multiuse platform. Fcr others, the mission could have been accomplished on a space platform; however, without the frequent, low-cost access to space afforded by a small tiaissions program, it is questionable whether the instrumentation or its associated scientific discipline would have ever matured to the point of being a contender for space on Eos. These points can be demonstrated best by reviewing some of the past earth science satellites that were not launched under the Explorer program, but that nevertheless represent the kinds of inissions that could be flown in the future under a new Easth Explorer line. 


\begin{tabular}{|c|c|c|}
\hline Explorer No. & Date & Mission Objective \\
\hline 1 & 1958 & $\begin{array}{l}\text { *Designed to obtain data on cosmic rays, } \\
\text { meteoroids, and orbital temperatures; discovered Van } \\
\text { Allen Beits }\end{array}$ \\
\hline 2 & 1958 & Follow-on to Explorer 1 - failed to orbit \\
\hline 3 & 1958 & Cosmic ray/flight test \\
\hline 4 & 1958 & ${ }^{*}$ Measurement of radiation belts \\
\hline 5 & 1958 & ${ }^{*}$ Foilow-on to Explorer 4 - failed to orbit \\
\hline s1 & 2959 & ${ }^{*}$ Study of energetic particles - failed to orbit \\
\hline 6 & 1959 & $\begin{array}{l}\text { "First TV picture of Earth, cloud cover; mapped } \\
\text { Earth's magnetic field }\end{array}$ \\
\hline 7 & 1959 & *Magnetic field, solar flares \\
\hline$S-46$ & 1960 & "Study of energetic particles - failed to orbit \\
\hline 8 & 1960 & $\begin{array}{l}\text { *Ionospheric electron measurements - confirmed } \\
\text { existence of He layer in upper atmosphere }\end{array}$ \\
\hline$S-56$ & 1960 & *Density of Earth's atmosphere - failed to orbit \\
\hline 9 & 1961 & $\begin{array}{l}\text { *Upper atmosphere/air density measurements } \\
\text { (Air Density Explorer) }\end{array}$ \\
\hline$S-45$ & 1961 & *Ionosphere messurements - failed to orbit \\
\hline 10 & 1961 & Magnetic field, solar wind \\
\hline 11 & 1961 & Gamma ray astronomy \\
\hline$S-45 a$ & 1961 & $\begin{array}{l}\text { *Determine the shape of the ionosphere - failed to } \\
\text { orbit }\end{array}$ \\
\hline S-55 & 1961 & $\begin{array}{l}\text { Measure micrometeoroids in low earth orbit - failed } \\
\text { to orbit }\end{array}$ \\
\hline 12 & 1961 & $\begin{array}{l}\text { *Radiation, solar winc, and magnetospheric } \\
\text { measurements }\end{array}$ \\
\hline 13 & 1961 & Micrometeoroid measurements \\
\hline 14 & 1962 & Magnetospheric measurements \\
\hline 15 & 1962 & $\begin{array}{l}\text { "Atmospheric radiation measurements caused by high } \\
\text { altitude nuclear test }\end{array}$ \\
\hline 16 & 1962 & Statistical sample of micrometeorites \\
\hline 17 & 1963 & $\begin{array}{l}\text { *Atmosphere density measurements - discovered belt } \\
\text { of neutral He atoms around the earth. }\end{array}$ \\
\hline 18 & 1963 & $\begin{array}{l}\text { Interpianetary Monitoring Platfnrm (IMP) Explorer - } \\
\text { support for Apollo program }\end{array}$ \\
\hline 19 & 1963 & *Air Density Explorer \\
\hline S-66 & 1964 & $\begin{array}{l}\text { *lonospheric and geodetic experiments - faired to } \\
\text { orbit }\end{array}$ \\
\hline 20 & 1964 & *Ionosphere electron distribution \\
\hline 21 & 1964 & IMP Explorer \\
\hline 22 & 1964 & *Ionospheric and geodetic measurements \\
\hline 23 & 1964 & Meteoroid measurements \\
\hline $24 / 25$ & 1964 & *Air Density Explorers (2) \\
\hline 26 & 1964 & ${ }^{*}$ Radiation particle and magnetospheric measurements \\
\hline 27 & 1965 & "Ionospheric and geodetic measurements \\
\hline 28 & 1965 & $\begin{array}{l}\text { Interplanetary Monitoring Platform (IMP) } \\
\text { Explorer }\end{array}$ \\
\hline 29 & 1965 & *Geodetic Explorer : GEOS-A \\
\hline 30 & 1965 & Solar radiation studies \\
\hline 31 & 1965 & "Composition and temperature of the ionosphere \\
\hline 32 & 2966 & $\begin{array}{l}\text { "Atmosphere Explorer determined the } \mathrm{He} \text { and } \mathrm{H} \text { ion } \\
\text { distribution in the lower exosphere }\end{array}$ \\
\hline
\end{tabular}


TABLE 3.1 (continued)

\begin{tabular}{|c|c|c|}
\hline Explorer No. & Date & Mission Objective \\
\hline 33 & 1966 & IMP Explorer \\
\hline 34 & 1967 & IMP Explorer \\
\hline 35 & 1967 & IMP Explorer \\
\hline 36 & 1968 & *Geodetic Explorer : GEOS-B \\
\hline 37 & 1968 & Solar radiation studies \\
\hline 38 & 1968 & Radio Astronomy Explorer \\
\hline $39 / 40$ & 1968 & *Air Density Explorers (2) \\
\hline 41 & 1969 & IMP Explorer \\
\hline 42 & 1970 & Small Astroncmy Satellite \\
\hline 43 & 1971 & IMP Explozer \\
\hline 44 & 1971 & Solar radiation studie \\
\hline 45 & 1971 & "Study of auroral phenomena and magnetic storms \\
\hline 46 & 1972 & Meteoroid studies \\
\hline 47 & 1972 & IMP Explorer \\
\hline 48 & 1972 & Small Astronomy Satellite \\
\hline 49 & 1973 & Radio Astronomy Explorer \\
\hline 50 & 1973 & IMP Explorer \\
\hline 51 & 1973 & $\begin{array}{l}\text { *Atmosphere Explorer - study of upper atmospheric } \\
\text { processes }\end{array}$ \\
\hline 52 & 1974 & $\begin{array}{l}\text { *Interaction of lar wind with Earth's magnetic } \\
\text { field }\end{array}$ \\
\hline 53 & 1975 & Small Astronomy Satellite \\
\hline 54 & 1975 & $\begin{array}{l}\text { Atmosphere Explorer - study of heat balance of the } \\
\text { atmosphere }\end{array}$ \\
\hline 55 & 1975 & $\begin{array}{l}\text { *Atmosphere Explorer - ozone measurements in upper } \\
\text { atmosphere }\end{array}$ \\
\hline DAD & 1975 & Dual Air Density Explorer - failed to orbit \\
\hline ISEE $1 / 2$ & 1977 & International Sun-Earth Explorers 1 \& 2 \\
\hline IUE & 1978 & International Ultraviolet Explorer \\
\hline $\begin{array}{l}\text { ISEE } 3 \\
\text { AEM-1 }\end{array}$ & $\begin{array}{l}1978 \\
1978\end{array}$ & International Sun-Earth Explorer 3 \\
\hline AEM-2 & $\begin{array}{l}1978 \\
1979\end{array}$ & $\begin{array}{l}\text { Heat Capacity Mapping Mission } \\
\text { "Stratospheric Aerosol \& Gas Experiment (SAGE) }\end{array}$ \\
\hline $\mathrm{DE} 1 / 2$ & 1981 & $\begin{array}{l}\text { "Dynamic Explorers } 1 \& 2 \text { - designed to investigate } \\
\text { the impact of solar radiation on the atmosphere, } \\
\text { auroral displaye, and climate and weather }\end{array}$ \\
\hline SME & 1981 & $\begin{array}{l}\text { auroral displays, and climate and weather } \\
\text { "Solar Mesosphere Explorer - provided data on } \\
\text { mesospheric ozone }\end{array}$ \\
\hline CRIE & 1982 & Cosmic Ray Isotope Experiment \\
\hline IRAS & 1983 & Infrared Astronomy Satellite \\
\hline $\begin{array}{l}\text { AMPTE } \\
\text { San Marco-D }\end{array}$ & $\begin{array}{l}1084 \\
1988\end{array}$ & $\begin{array}{l}\text { Active Magnetospheric Particle Tracer Explorers (2) } \\
\text { *Study relationship between solar radiation and } \\
\text { meteorological phenomena - } 2 \text { spacecraft launched }\end{array}$ \\
\hline
\end{tabular}

- Denotes missions with earth science objectives, which are defined here to include all environmental processen from the magnetosphere to the Earth's surface.

Source: Ron Teeter and Mark Kuhner, Final Report on the OSS Explorer Program: A Status Review -- Volume II: Explorer Mission Summaries, Battelle $(1980)$ 


\section{Laser Geodynamics Satellite (LAGEOS)}

The Laser Geodynamics Satellite (LAGEOS), the first U.S. satellite developed exclusively for geodynamic measurements using laserranging techniques, is one oi the simplest and cheapest satellites ever built. It was launched in 1976 at a cost of approximately $\$ 6$ million* into an orbit with a height of about $6000 \mathrm{~km}$ and an inclination of $109.8^{\circ}$. Its operational lifetime is estimated at several million years. The satellite is a sphere, $60 \mathrm{~cm}$ in diameter, having a mass of about $407 \mathrm{~kg}$, and is covered with 422 corner reflectors of fused silica and 4 of germanium. The reflectors allow ground-based 'ssers to track the position of the satellite with centimeter accuracy.

Data from laser ranging to this satellite have contributed more information on solid earth geodynamics than have the data obtained from all of the previous satellites. They have provided the most accurate model of the long-wavelength components of the Earth's gravitational field, which in turn has significantly enhanced our ability to determine the positions of all other artificial Earth orbiters. The orbit of LAGEOS is known so precisely that laser ranging to the satellite can be used to refine the positions of the tracking stations in geocentric coordinates with accuracies approaching $1 \mathrm{~cm}$, and to calculate motion of the tracking stations due to tectoric deformation, changes in the length of day, and changes in the position of the pole. Knowledge of those changes has been improved by factors of 10 to 100, making possible studies of the globsl geophysical processes influencing these variables, such as postglacial rebound, electromagnetic coupling between the core and mantle, and angular momentum exchange between the atmosphere and solid earth. Some of the exciting results from LAGEOS measurements are contained in the 1985 special issue of the Journal of Geophysical Research on LAGEOS.

The immense success of L,AGEOS has led to the development of at least one additional, identical satellite. LAGEOS-II is being built in cooperation with the Italian space agency at a cost of $\$ 3$ million to NASA and is expected to be launched in 1991 into a similar high-altitude orbit, but with lower inclination $\left(51^{\circ}\right)$. This cooperative effort will provide at an extremely modest cost more

*All costs for past missions are adjusted for inflation and given in 1987 dollars. They include hardware development costs only (Phases A-D), and exclude launch and mission operations and data analysis (MO\&DA) expenditures. 


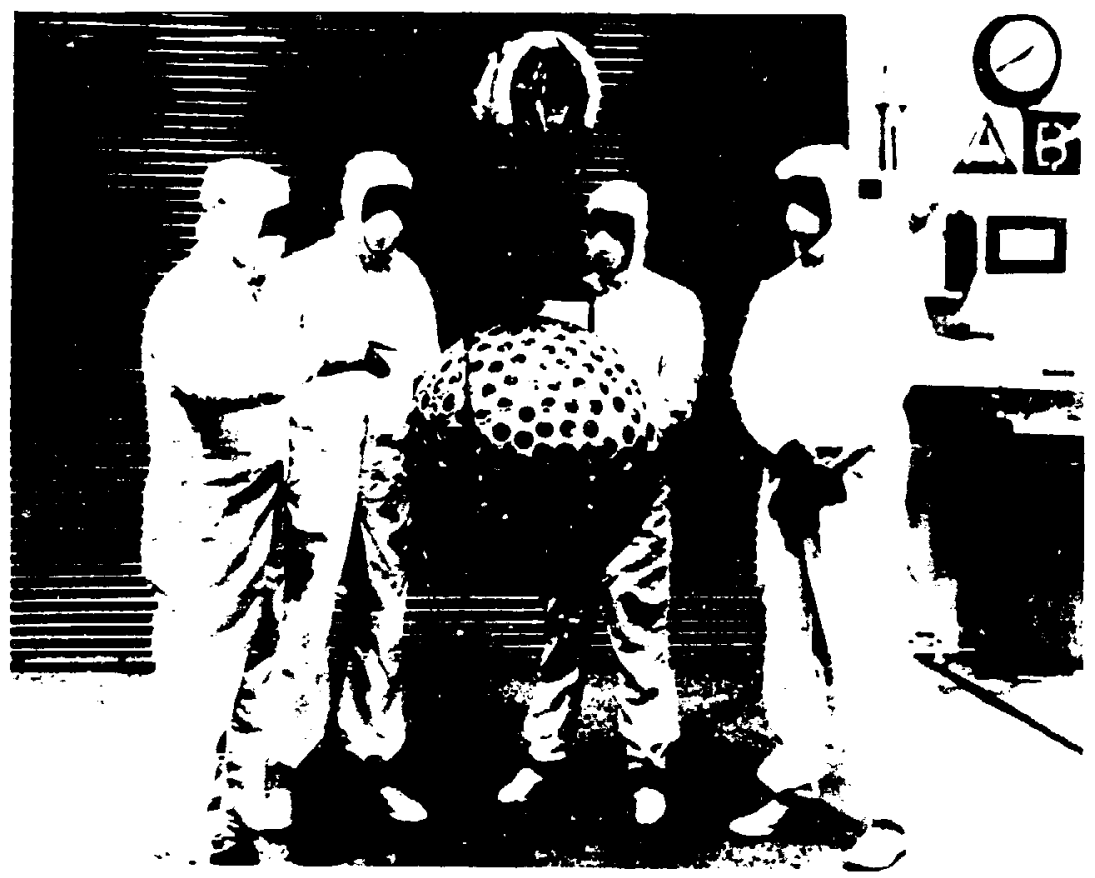

NASA personnel inspecting the Laser Geodynamics Satellite at the Marshall Space Flight Center several months before launch. (Photo courtery of NASA.)

accurate baseline lengths, improved knowledge of long-wavelength variability of Earth's gravitational field, and better tidal models.

Other nations have also taken advantage of the LAGEOS-type satellites. International cooperation in satellite laser ranging bas extended to the Starlette satellite launched by the French space agency, CNES, in 1976 and to the AJISAI satellite launched by the Japanese space agency in 1986. The French are currently planning another polar-orbiting Starlette-class satellite for the late $1980 \mathrm{~s}$ to enhance studies of the Earth's gravitational field and ocean tides.

LAGEOS has so conclusively demonstrated the effectiveness of laser ranging for geodynamic positioning that a space-borne laser is proposed for Eos that will range to corner-cube reflectors on the ground. This will avoid the acquisition costs of new lasers that are necessary when an additional permanent ground station is added to the satellite laser-renging network. Although some geodynamic positioning may be accomplished in the future from a space platform, 
two facts relevant to the merits of an Earth Explorer program must be kept in mind. First, the feasibility of laser positioning from space might never have been demonstrated without the opportunity for low-cost access to space available for LAGEOS. Second, LAGEOS was successful only because it was launched into such a high, stable orbit that the lack of an adequate gravity field model for the Earth at shorter wavel angths did not interfere with the ability to provide absolute positioning.

\section{Magsat}

The Magsat mission produced the first high-resolution global maps of the Earth's magnetic field. The $\$ 39$ million satellite measured the vector components of the planet's magnetic field at the height of the satellite with an accuracy of 6 nanoTesla (about 0.01 percent of the total field). It was placed in a sun-synchronous orbit at an inclination of $96.76^{\circ}$ and an altitude that varied from 350 to 550 $\mathrm{km}$. The satellite's projection onto the surface of the Earth passed within $300 \mathrm{~km}$ of every location (except for two polar caps with radius of $450 \mathrm{~km}$ or $4^{\circ}$ ) more often than once a week. The magnetic field vector components were each sampled at a maximum rate of 16 times per second, and the satellite was operational during the period October 1979 through July 1980. The accuracy and distribution of the samples allowed calculation of the spatial variability of the magnetic field with wavelengths as short as $800 \mathrm{~km}$ on the Earth's surface. The global maps of the Earth's magnetic field provided by Magsat exceeded prelaunch expectations, with the main field defined to better than 20 nanoTesla.

One other database for satellite measurements of the Earth's magnetic field was provided by the Orbiting Geophysical Observatory (OGO) during a period of several years in the late 1960s. These data were total intensities only, without vector components, and were mathematically insufficient to determine the magnetic field in the region where they were obtained. Except for these satellite data the maps of the magnetic field before Magsat were based on information from a worldwide network of about 200 magnetic observatories at the Earth's surface, but the observatories were not well distributed. For example, no data were available from within a $10,000-\mathrm{km}$-wide gap in the South Pacific. As a result, data from the observatories were of limited use for global studies. 


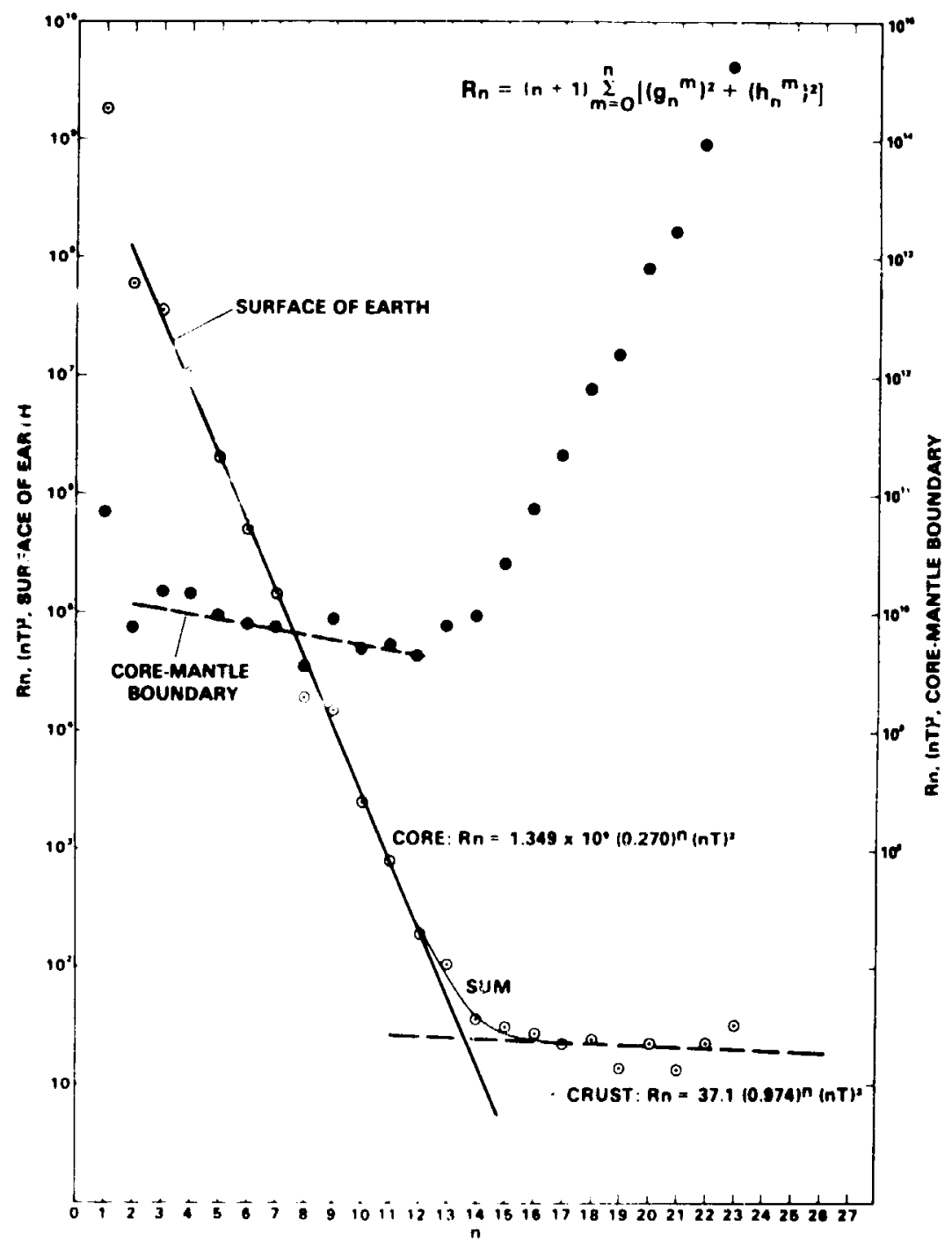

FIGURE 3.1 The mean-square value of the geomagnetic field of the nth harmonic degree at the surface of the Earth and at the core-mantle boundary, obtained from Magsat data. This part of the field has horizontal wavelength $2 \pi \mathrm{a} / \mathrm{n}$ on a sphere of radius a. The two straight lines suggest that there are two source regions. For $n<14$ the source at the depth of the core-mantle boundary dnminates the field, while for $n>14$ the source at the radius of the Earth's crust is more important. SOURCE: R.A. Langel and R.H. Estes, "A Geomagnetic Field Spectrum," Geophysical Rescarch Letters 9, 250.253 (1982). 
Spatial spectra of the magnetic field made from Magsat measurements provided, for the first time, a widely accepted basis for separation of the magnetic field due to processes in the Earth's core from that of the crust. A sample of these results is provided in Figure 31 . The observations of the core's field enabled studies of the motion of the fluids in the core and the electrical conductivity of the lower mantle, while the observations of the crust showed strong fields near Yellowstone, the Rio Grande rift, and some previously unnoticed anomalies interpreted as undiscovered rifts in other continents. The Magsat data also made possible the measurement of the small-scale magnetic fields near magnetic observatories. Corrections for these local biases made old observatory data more useful for studies of the core field as it existed one or two centuries ago.

Magsat is an excellent example of the type of scientific mission that could not have been performed from a space platform and that may never be followed up without an Earth Explorer line. Resolving the high-frequency components of the crustal field requires an orbital altitude below $450 \mathrm{~km}$, a level that does not allow sufficient mission duration for a major space platform. In addition, the magnetometer sensor must be far removed fron the local field induced by space hardware in order to measure variations in the Earth's field. Frequent magnetic missions or those of long duration will be required in the future for monitoring temporal variations of the core field, which is efficiently measured from space. Therefore, without provision for launching such magnetometers, prospects are dim for significant advancement in our understanding of the Earth's magnetic field.

\section{Nimbus Series}

The series of seven Nimbus satellites, launched between 1964 and 1978, demonstrated the great scientific and technologir ${ }^{\prime}$ ' Jrogress that follows from the flight of a series of similar sate... program provided the first global observations of many impurtant processes. Examples include observations of the time variation of temperature, c.one, and water vapor in the atmosphere and stratosphere; the exient of ice in the Arctic and Antarctic as well as a basic description of ice types; the variability of ultraviolet light from the Sun; the distribution of chlorophyll in the oceans and the relationship of marine phytoplankton to oceanic conditions; and the distribution of sea surface temperature. Nimbus 7, operating well beyond its design lifetime, has provided the maps of the ozone column 

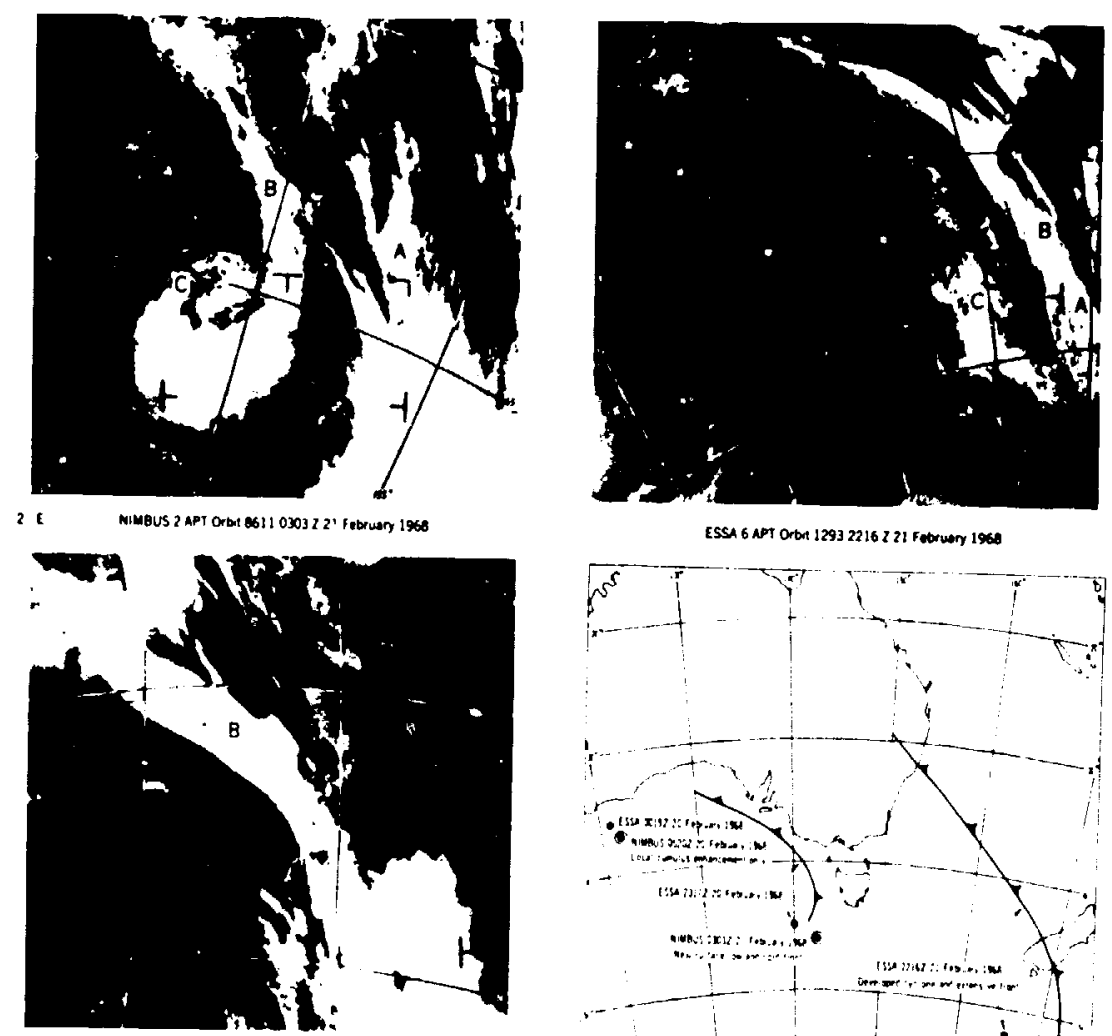

ESSA 6 NPT Oron 12932216231 Foterwory 1960

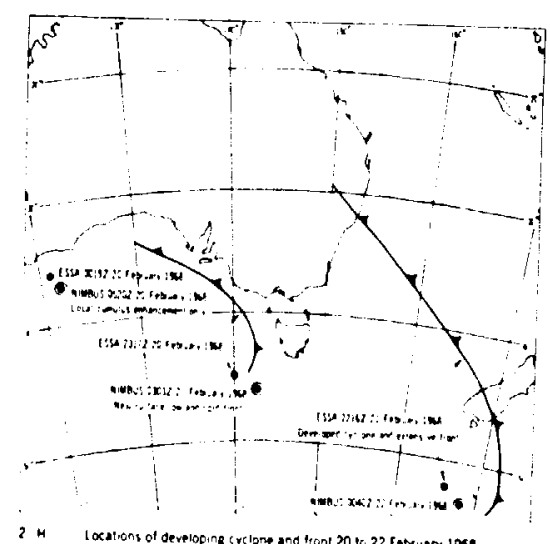

SESSION 20

FIGURE 3.2 Sequence of local readout visible-wavelength Nimbus satellite inages showing the mature and decaying stages of a baroclinic cyclone that passed south of Tasmania and New Zealand on Feiruary 21-22, 1968. SOURCE: J.W. Zillman, Space Science and Engineering Center, University of Wisconsin.

over Antarctica required to define the "ozone hole" and follow its evolution during the last decade. The program also developed many of the Earth-observing instruments flown later on operational satellite systems, particularly the NOAA meteorological satellites. Figure 3.2 provides an example of its meteorological application. The success of this series of satellites made the United States the world leader in remote sensing of the atmosphere and the ocean.

The Nimbus satellites were all related in design, but became increasingly heavier and more complex as the system evolved, with satellite mass increasing from $380 \mathrm{~kg}$ to $990 \mathrm{~kg}$. Each operated in a 
sun-synchronous orbit at an altitude near $1100 \mathrm{~km}$, except for the first. The use, however, of similar satellite structures, control systems, and data systems led to reductions of cost compared with other satellite systems of similar complexity. In addition, the inheritance of designs and hardware led to remarkably long-lived satellites, many of which substantially outperformed their design life.

There are several characteristics of the Nimbus satellites that are relevant in the Earth Explorer context. They demonstrated the value of small satellites, performing high-quality science, to the development of instruments for oderational status. They also offered university scientists and graduate students unique research opportunities, bringing the United States to the forefront of those disciplinary areas. Finally, they provided useful experience in the production of standardized spacecraft and technological inheritance. The committee would like to emphasize, however, that the Earth Explorer program should not become a vehicle for establishing a long-term series of missions whose sole purpose would be to continue one set of repetitive measurements. Such a function must be performed by the operational agencies in the United States and abroad.

\section{Radar Altimeters: GEOS-3, Seasat, and Geosat}

The goal of the radar altimeter missions in the 1970 s was to improve our knowledge of Earth's gravitational field: the marine geoid, sea state, ocean currents, crustal structure, solid earth dynamics, and remote sensing technology. The $\$ 96$ million GEOS-3 was launched irto an orbit with an inclination of $115^{\circ}$ and a height of $844 \mathrm{~km}$. It carried a new advanced radar altimeter, radio tracking systems, and corner reflectors to allow tracking of the satellite br ground-based lasers. Data from the radar altimeter and tracking systems were used to map the marine geoid with an accuracy of a few meters and a precision of a few tens of centimeters in areas where the satellite was within sight of fixed or mobile telemetry stations. No data were stored onboard the satellite. In addition, data from the altimeter were used for mapping ocean wave height and ocean surface wind speeds.

The information provided by GEOS-3 made important contributions to our knowledge of the marine geoid, farticularly in the northwest Atlantic and parts of the Pacific Ocean where the grid of altimeter observations is most dense. The most notable contributions were determinations of the strength of the oceanic lithosphere 
at a number of locations, the first direct observations of the slope of sea level due to strong ocean currents, and global maps of monthly averaged wave height. A special issue of the Journal of Geophysical Research (GEOS-3, 1979) contains numerors research papers based on GEOS-3 data.

The immense success of GEOS-3 led immediately to a subsequent mission, Seasat, which incorporated a more precise altimeter. At a cost of $\$ 174$ million, the satellite returned a wealth of new data on the geoid, wave height, wind speed, and water vapor content over the oceans despite the mission's premature termination following a mechanical failure. Differences of sea surface height measured over repeat tracks provided the first viow of the time-dependent sea surface components due to dynamic oceanographic effects. As a result of the Seasat and GEOS-3 altimeters, earth scientists were able to know the marine geoid better than the bathymetry in many regions, particularly in the South Atlantic, South Pacific, and Indian oceans.

Tectonophysicists capitalized on this information to study the mechanical properties of the lithosphere, the thermal structure of plates, the dynamics of midocean ridges, and the scales and patterns of mantle convection. The geoid was used to predict the location of uncharted seamounts, revise the coordinates of mislocated bathymetric features, and trace the position of fracture zones for plate reconstructions. Some of the scientific payoff from Seasat is contained in several special issues of the Journal of Geophysical Research (Seasat I, 1982; Seasat II, 1983; Origin and Evolution of Seamounts, 1984), and this data set continues to be used in many studies.

Radar altimeter missions are an outstanding example of how the scientific benefits of a mission can be maximized by having complete control over the orbit for an individual sensor package. In the case of Seasat, part of the mission was designed to provide repeat ground tracks for viewing the time-dependent sea surface elevation, whereas during the rest of the mission the altimeter covered new ground to provide finer resolution in the determination of the time-independent geoid.

The committee notes, however, that Seasat was much larger, more complex, and more expensive than any Explorer-class mission. The Geosat radar altimeter program, which builds upon the Seasat mission, is a simple $\$ 45$ million spacecraft that operates in the special Seasat orbit. See Figuie 3.3 for an example of comparative data from the Seasat and Geosat missions. This satellite, like GEOS-3, 


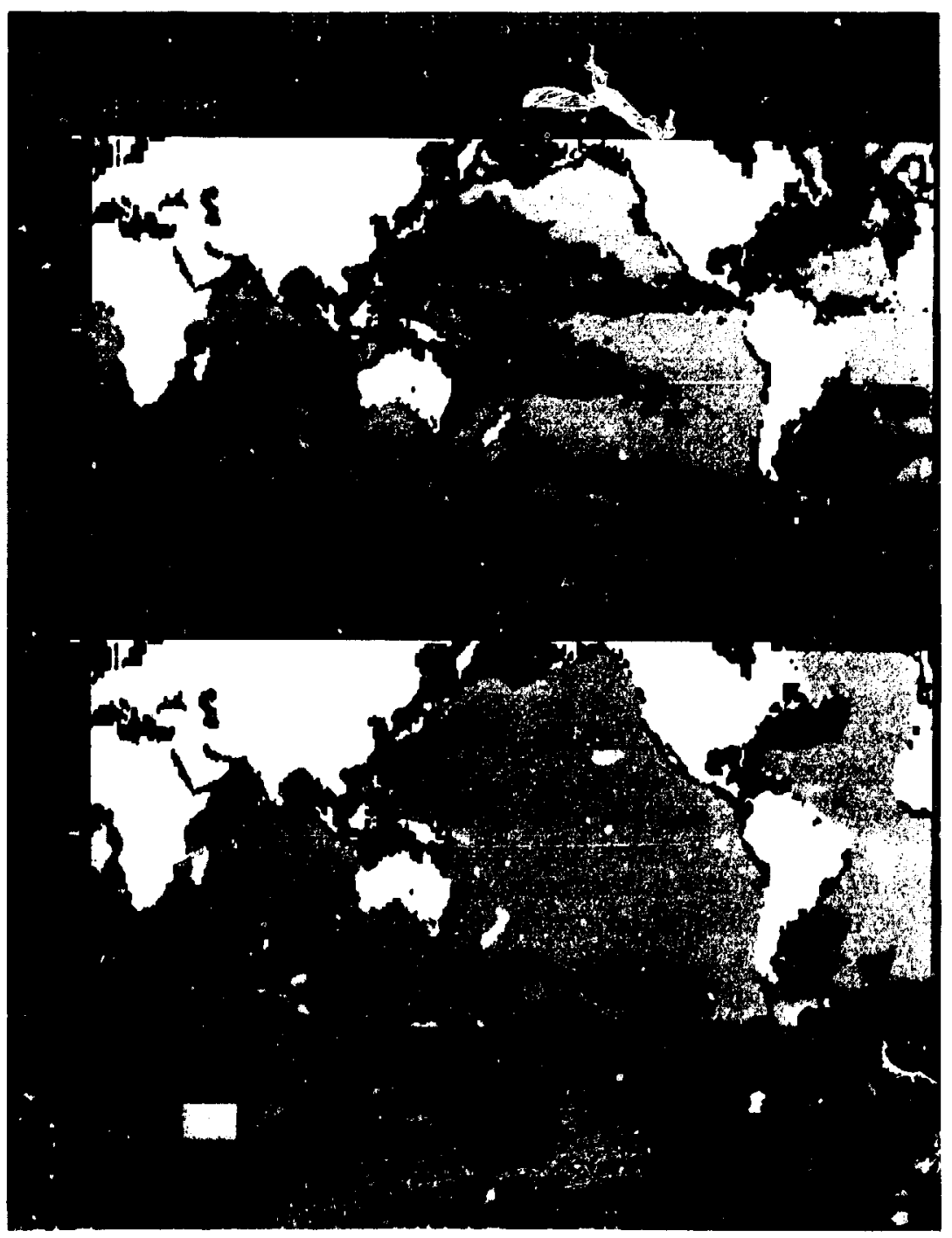

FIGURE 3.3 This figure shows the gic bal mesoscale (50 to $1000 \mathrm{~km}$ ) sea level variability from the Geosat ind Seasat altimeter measurements. The lower figure provides an estimate of the root-mean-square (rms) variability derived from Seasat from September 16 to October 10, 1978. The upper figure shows a recent estimate derived from Geosat over a one-year period from November 8,1986 to Novomber 17, 1987. The analysis depicts the variations in sea level caused by wavelengths between 35 and $1500 \mathrm{~km}$, and demonstrates the dramatic improvement in resolution that is being provided by Geocat. The Geosat observations have discovered a number of secondary regions of sea level variability ( 7.5 to $15 \mathrm{~cm} \mathrm{rms}$ ) that were not resolved by Seasat, principally in the equatorial current system, and subtropical regions of both hemispheres. SOURCE: C. Koblinsky, NASA Goddard Space Flight Center. 
corresponds more closely to the type of mission and level of expense envisioned for the Earth Explorer series. Although an altimeter is scheduled for Eos, the flexibility in orbit design afforded in the previous missions will be sacrificed for the sake of mounting the instrument on a multipurpose, sun-synchronous platform with a fixed 5 -day repeat. Thus the Eos altimeter will do little to fill in the $100-\mathrm{km}$ gaps in the marine geoid remaining after Seasat's untimely demise, or that remain even with Geosat data.

\section{Earth Radiation Budget Expariment}

The Earth Radiation Budget Experiment (ERBE) was designed to measure the energy exchange of the Earth with the Sun and space as precisely as yossible. Accurate knowledge of the radiative exchange of energy between the Earth and its environment and understanding of the processes that control that exchange are necessary prerequisites to reliable predictions of the effect of increased greenhouse gases on the energy balance of the Earth. The radiation exchange is particularly important for understanding the role of clouds in the maintenance of the Earth's climate. Because of diurnal variations in solar zenith angle, clouds, temperature, and humidity, cycle. To of radiation must be made over the full 24-hour diurnal observing system was dequate sampling of that cycle, a multisatellite three identical flight designed for the ERBE with the construction of sun-synchronough instruments. Two of these were flown on NOAA the third set of instrumg and afternoon operational satellites, and lite (Elass). The combination of the Earth Radiation Budget Satela non-sun-synchronous satellite two sun-synchronous satellites and complete diurnal sampling (see Figure 3.4 global coverage with tation of the coverage). Each instrument package contaic represeninstrument, a nonscanning wide-field-of-view instrument, and a solar be separated from oth instruments allow the effects of clouds to calibration is maintained effects on the radiation balance. Absolute as reference sources.

The FRBS was lau 1984, and inserted into anched by the Space Shuttle on October 5, ERBS precesses through local inclination orbit. The orbit of the can be sampled in 37 days. The FRBS that the entire diurnal cycle Aerosol and Gas Experiment II (SAGE-II), carries the Stratospheric 


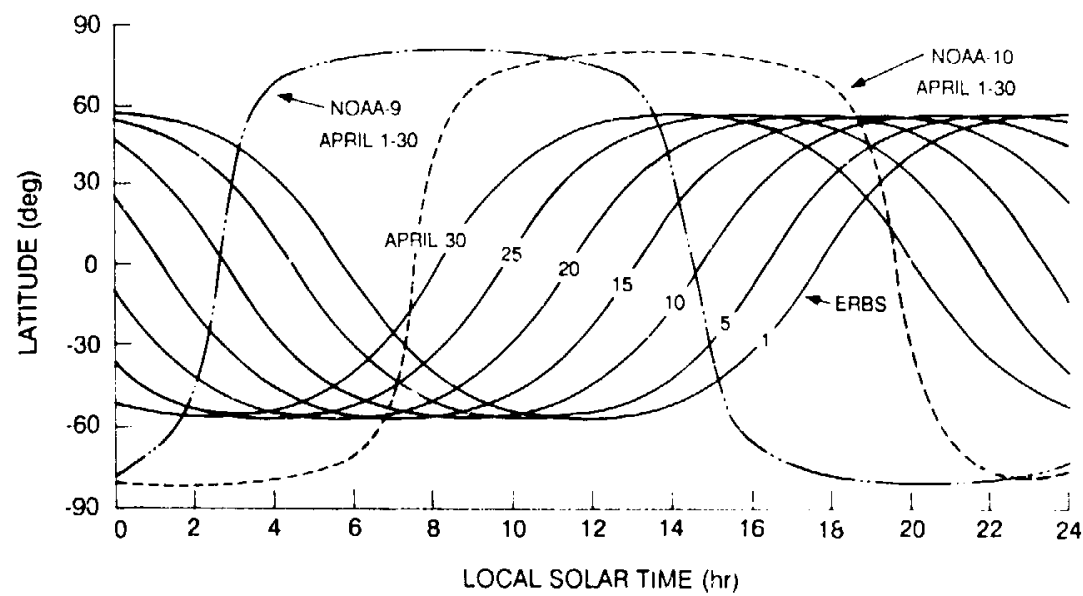

FIGURE 3.4 Latitude and local time coverage for satellites in different ortits for ERBS. SOURCE: E.F. Harrison, NASA Langley Research Center.

ozone, and other gas concentrations in the stratosphere using a solar occultation technique. SAGE-I was launched as an Explorer mission in 1979. Because the ERBS crosses the sinrise and sunset terminators at all latitudes less than $57^{\circ}$, it makes a good platform for the $S: G E-I I$ instrument, which takes its measvrements during these crossings. ERBE data have been used to produce the first direct measurements of the forcing of the climate system by clouds. It is also the first experiment to measure the full diurnal variation of broad-band radiative energy fluxes.

The ERBE experiment provides an example of several features of the proposed Earth Explorer line of satellite experiments. It responded to an urgent scientific need for better data on the role of clouds in the radiation balance, while remaining within a modest budget (\$61.6 million for the ERBS and \$19 million for each of the ERBE instruments). The experiment provided a source of high-quality geophysical data during a time when relatively few new instruments were being flown. Because the need for diurnal sampling of the globe could not be filled within the framework of current operational or research flight opportunities, a small special-purpose orbital vehicle was developed and launched. In order to further improve the sampling, identical instruments developed by NASA were flown aboard NOAA operational platforms. This interagency cooperation greatly enhanced the capability of the measurement system at modest cost. 


\section{PROSPECTIVE MISSIONS}

A number of proposed missions are candidates for becoming Earth Explorers. Some carry sensitive instruments that cannot operate on a multiuse spaceiraft. Others require different orbital altitudes or inclinations froin those of the Eios platform. and other cperational satellite iystems, or they irclude instruments that could be developed for flight on satellites rperated by other space agencies. They all provicie measurements critical for Earth System Science stucies and have been strongly recommerded by the scientific community. The commit tee e:nphasizes, however, that these prospective missions are rot discussed in any order of priority or in any comprehensive manner and are merely represen'ative of the kinds of inissions that could be accumplished under an Earth Explorer line. What is cerlain is that without the establishment of such a line they stand little chance of ever being launched.

These missions are discussed under tino categories: (1) low-cost, lishtweight missions, tither single-instrument spacecraft or insirnments fiown as missions of opportunit;, that can be constructed in uncier 3 years for $\$ 30$ million or less; and (2) moderate-cost missions that either would be accomplish ad by NASA alcne within the com: nittee's proposed budgetary ceiling of $\$ 150$ millirn, or could be accommodated within the Explorer program by virtue of costreducing collaborations with other space agencies. (See the next chapter for a discussion of the committee's related recommendations and their justification.)

\section{Low-Cost, Lightweight Missions}

\section{Total Ozone Mapping Spectrcmeter}

The Total Ozone Mapping Spectrometer (TOMS) is an instrument designed to provide high-spatial-resolution maps of total ozone - the amount of ozone integrated over the depth of the atmosphere at a given location. Day-to-day variations in total ozone are closely related to dy namical processes near the tropopause. Since most of the ozone is in the lower stratosphere, where chemical sources and sinks are slow in comparison with changes produced by motions, high-resolution maps oi total ozone provide considerable information about advective processes in those areas. On longer time scales, TOMS can be used to measuro temporal trends in total ozone. Such 


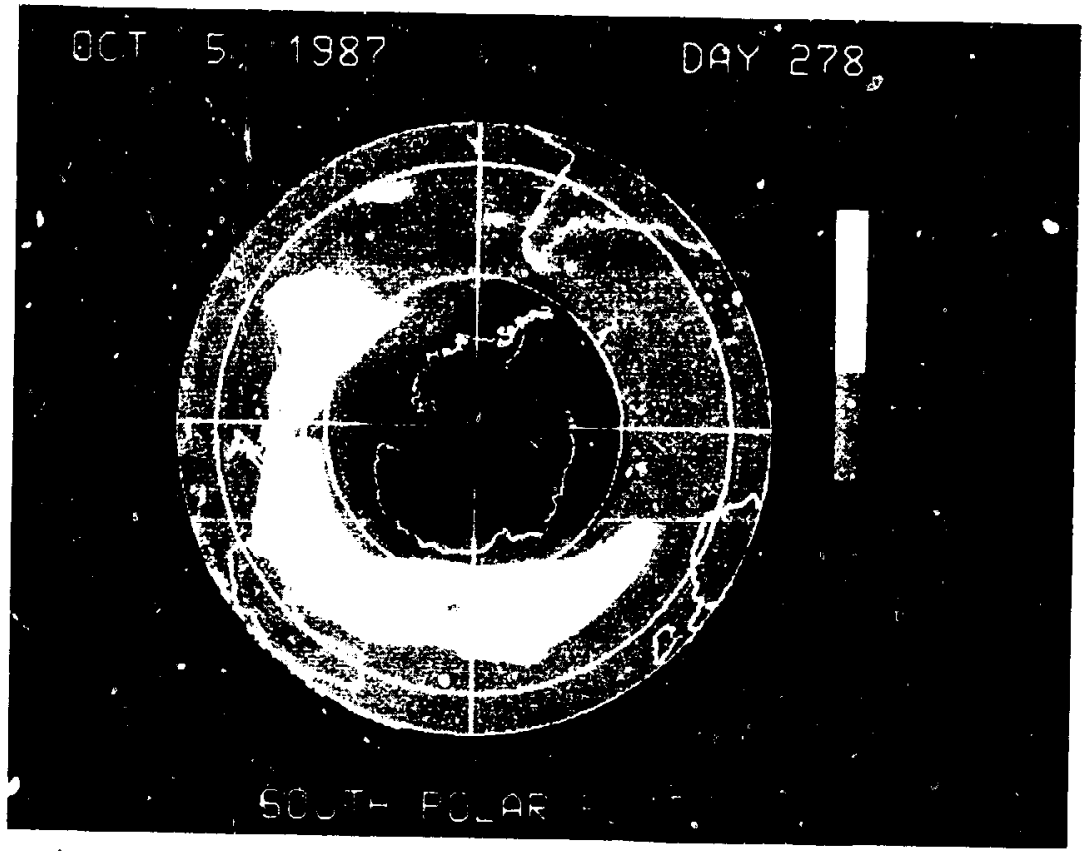

FIGURE 3.5 This Southern Hemisphere plot of total osone distribution for October 5, 1987, shows a value of appro:imately 125 Dobson Units (DU) (black), the lowest osone value of 1987 to date and the lowest total osone value ever observed. This plot also shows that the osone hole is nearly half the area of the Antarctic continent, an ares covering approximately 7 million square kilometers (2.5 million square miles). The data were taken with the Total Osone Mapping Spectrometer (TOMS) instrument on NASA's Nimbus 7 satellite, which is managed by the Goddard Space Flight Center. The values of the colore in DU of total units are shown in the color bar. SOURCE: A.J. Krueger, NASA Guddard Space Flight Center.

trends are expected to occur in association with changes in the chemistry of the stratosphere induced by the release of industrial gases.

A. TOMS instrument has been in orbit on the Nimbus 7 satellite since No:ember 1978, providing daily maps of total ozone with $50-\mathrm{km}$ spatial resolution. Data from this instrument have been invaluable in documenting the rapid decline in total ozone over Antarctica during the spring season. For example, Figure 3.5 shows the total ozone distribution for October 5, 1987-the lowest total ozone value ever observed. The TOMS instrument has already operated well beyond its expected lifetime and could fail at any time. Because of the serious ramifications of the ozone reduction phenomenon, the usefulness of 
the TOMS data in monitoring the problem on a global scale, and the lack of any firm plans to fly a similar instrument in the near future, an ozone-measuring instrument is a high-priority payload for the proposed Earth Explorer line of satellites. This is consistent with the 1985 CES strategy's highest priority scientific objective for the study of the middle atmosphere, which was to measure continuously tota! ozone and its vertical profile over the globe with sufficient accuracy to test theoretical predictions.

An engineering model of the TOMS instrument is currently available and could be flown on short notice with only minor modifications. The spectrometer could be launched either as a singleinstrument mission on a Scout-class rocket or with other instruments on another U.S. or foreign spacecraft. The cost of modifying the existing instrument for launch readiness is about $\$ 7$ million. The committee emphasizes that global ozone measurements are too important to allow the lengthy data gap that is projected to occur between the failure of the Nimbus 7 system and the time when an Eos-mounted sensor is operational.

\section{Sea Wide Field Sensor}

The firs' instrument to measure chlorophyll from space was the Coastai Zone Color Scanner (CZCS) flown on Nimbus 7. It measured the radiance reflected from the ocean surface in the visible and nearinfrared and thermal infrared regions. Chlorophyll concentrations were derived by using data from the visible wavelengths, and sea surface temperatures were calculated from the infrared measurements. Data from the near-infrared band were used for atmospheric correction of the data acquired in the visible bands. Although the CZCS was designed as a "proof of concept" instrument with a one-year design lifetime, the instrument provided valuable information for almost 8 years, revolutionizing the field of global biological oceanography in the process. See Figure 3.6 for an example of CZCS results showing the relationship between satellite pigment concentrations and daily primary production.

A successor to the Coastal Zone Color Scanner on Nimbus 7 has been proposed for flight on the 1991 Landsat 6 mission. Called the Sea Wide Field Sensor (Sea WiFS), the instrument would map the distribution of chlorophyll in the upper layers of the ocean and collect sea surface temperature data crucial to understanding global-scale biological and physical processes. It would fly at an altitude of 705 
ZONAL PROLUCTIVITY - 1979

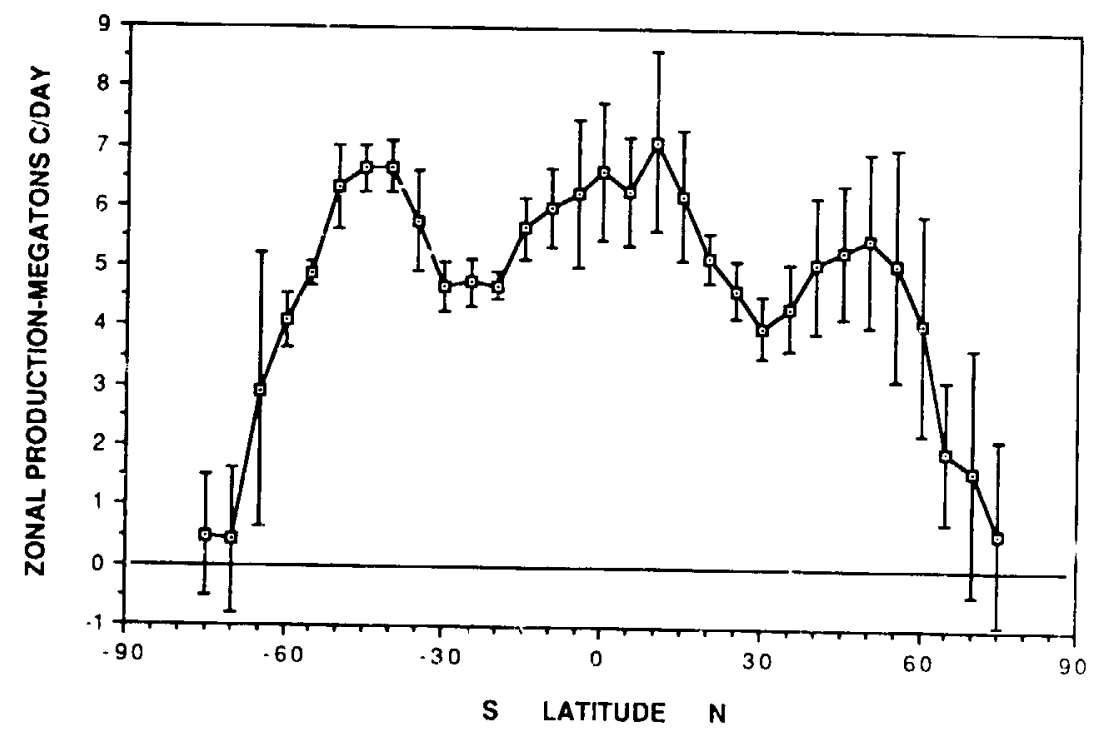

FIGURE 2.6 The relationship between satellite pigment concentrations and daily primary production (Eppley et al., 1984) was applied to all monthly CZCS pigment values for 1979 at $20-\mathrm{km}$ resolution, averaged zonally and normalized for total oceanic area within 5 degree sones. Error bars are l siandard deviation of 12-month values and are significantly greater in the Northern Hemisphere. The corresponding esticuate of global carbon fixation is 59 gigatons per year. SOURCE: W. Esaias, C. McClain, G. Feldman, NASA Goddard Space Flight Center.

$\mathrm{km}$ in a circular, polar, sun-synchronous orbit, with an equatorial crossing time of 10:30 a.m. Spatial resolution would be $1.13 \mathrm{~km}$ for local area coverage and $4.5 \mathrm{~km}$ for global area coverage.

The Sea WiFS would contribute to several of the highest priority objectives for global biogeochemical cycles, and for the study and prediction of long-term climatic changes ss set forth in the 1985 CES strategy. Among the most important observations by the sensor would be the magnitude and variability of the annual cycle of primary production by marine phytoplankton on a global scale; a quantitative assessment of the ocean's role in the global carbon cycle and in other biogeochemical cycles; the coupling between upwelling and largescale patterns of productivity in ocean basins; the distribution anc' timing oi spring blooms in the world's oceans; and the processes associated with mixing along the edges of eddies, coastal currents, 
and boundary currents. Increased understanding of these processes would be especially useful for the IGBP and Joint Global Ocean from the NASA/NOAA/EOSAT Field-of-View Observations of 1987).

At a cost of approximately $\$ 25$ million to NASA, the Sea WiFS could fly piggyback on Landsat 6 and cut in haif the 10-year gap in the termination variables that would otherwise exist between of new oc an color/sea surface tements in 1986 and the launch A flight in 1991 is particurface temperature instruments on Eos. instrument would complementy important because the Sea WiFS oceanographic spacecraft scheduled ineasurements made by other the European Space Agency's TOPEX/Poseidon mission (1992' 1 (1991) and the NASA/French tal data for major oceanon (1992; It would also provide fundamenthe early 1990s as part of the experiments now being planned for which includes the World the World Climate Research Program, Tropical Oceans and Glocean Circulation Experiment and the

Measurement of Air Pollution from Satellites

Carbon monoxide $(\mathrm{CO})$ constitutes over one-half of the total emissions that pollute the air in the United States. Approximately 50 percent of the total CO flux is estimated to come from industrial activity. Studies based on numerical models have shown that the $\mathrm{OH}$ chemistry and to produs sufficient to perturb global $\mathrm{CO}-\mathrm{CH}_{4}$ chemistry and planetary heat balance

The first global determination of within several decades.

dle and upper troposphere was made bO distribution in the midPollution from Satellites (MAPS) exper the Measurement of Air Space Shuttle flight, and again in experiment on a November 1981 the results from 1984). The in October 1984 (see Figure 3.7 for technique to maintain. The instrument used a gas filter correlation spectral resolution in thigh radiation throughput and high effective

The successful shuttle $4.67-\mu \mathrm{ma}$ fundamental band of $\mathrm{CO}$.

strument could be modifle experiment indicated that the MAPS inthe global distribution of of at least 1 year. The resulting the middle troposphere over a period 


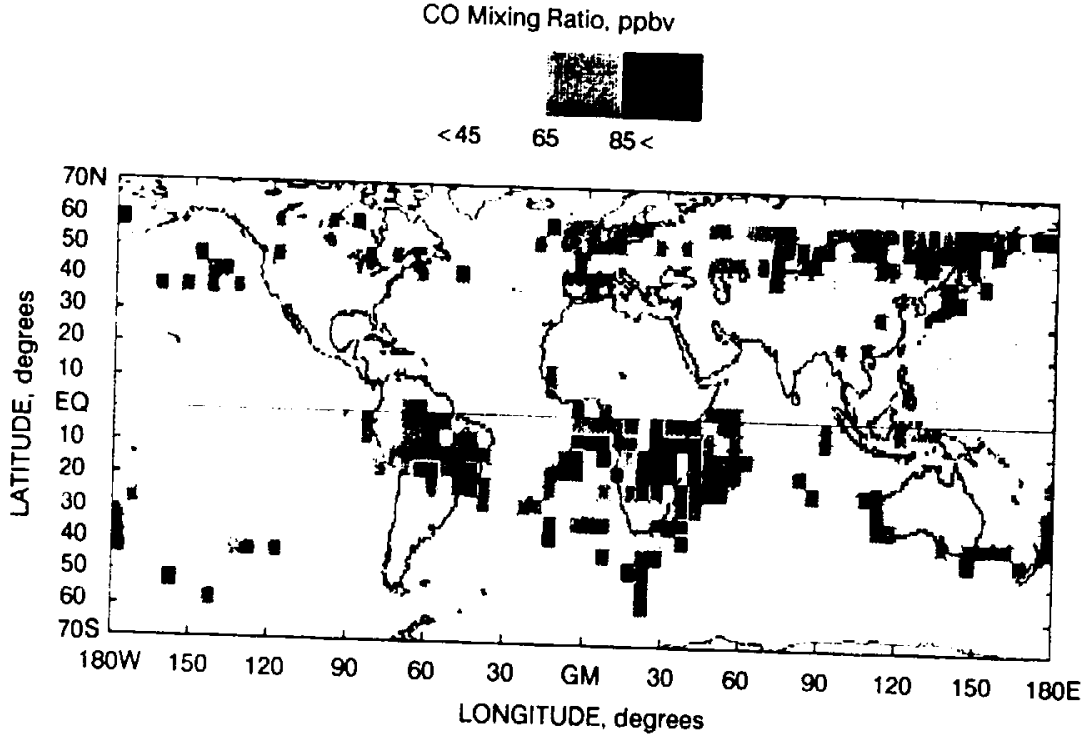

FIGURE 3.7 The distribution of carbon monoxide in the free troposphere provided by the Measurement of Air Pollution from Satellite (MAPS) experiment during October 5-13, 1984. SOURCE: H.G. Reichle, NASA Langley Space Flight

three-dimensional transport chemistry, define source regions, study tropical Walker and Hadley circulations, investigate the relationship between $\mathrm{O}_{3}$ and $\mathrm{CO}$ in the tropical troposphere, and determine the levels of interhemispheric exchange. The data would have high scientific value and would notably improve our overall understanding of trcpospheric dynamics and chemistry. The MAPS instrument could be modified for an Earth Explorer spacecraft or fly as a piggyback mission for approximately $\$ 7$ million.

\section{LAGEOS III}

A third LAGEOS satellite, LAGEOS III, has been proposed at the same orbital altitude and eccentricity as LAGEOS II, but with an inclination of $76^{\circ}$. This satellite, when used with LAGEOS I, would provide a stable reference frame for determining with high accuracy the variability of Earth's rotation to enable studies of the solid earth, atmospheric angular momentum, and energy exchanges with the atmosphere and core. It would also provide more accurate determinations of the positions of points on the Earth in support of 
global plate tectonic and crustal deformation studies. These were all high-priority objectives for the study of solid earth dynamics from space in the 1982 CES strategy.

\section{Moderate-Cost Missions}

\section{Magnetic Field Explorer}

The primary goal of the Magnetic Field Explorer (MFE) would be to monitor the changes in the field produced by the core that have taken place since the Magsat mission in order to study the secular variation of the Earth's magnetic field. The measurements should be made from an approximately polar orbit. The mission would sample the Earth's magnetic field at all local times to eliminate errors produced by the ionospheric field. The orbit should be higher than Magsat's to give the satellite a lifetime of at least 18 months, and preferably 3 years.

The magnetic field has interesting variability on all time scales, from minutes to a billion years. Variability induced by the motion of the Earth's core extends from 1 year to 10,000 years. A time series over several 11-year sunspot cycles is required for observing the electrical conductivity of the lower mantle by magnetic sounding. This duration is also necessary to see the temporal changes in the field with sufficient accuracy for inferring fluid velocities in the core and for attempting to observe a magnetic impulse like the one detected in 1970. Seeing such an impulse with good geographical coverage would provide important information about the dynamics of the Earth's core.

The $\$ 70$ million estimated cost, the specialized orbital requirements, the need for shielding from local spacecraft fields, and the desirability of frequent and repeated field monitoring all make the MFE an ideal candidate for an Earth Explorer mission. Discussions with representatives of the French space agency have indicated the possibility of doing MFE in conjunction with a French mission. This could demonstrate the feasibility and value of a permanent international satellite program for monitoring the magnetic field, observing events in the motion of the core, and compiling the statistics of the fluid motion in the upper core. Such a program would be the geomagnetic analog of the worldwide seismic network now in place for monitoring earthquakes and the structure of the upper layers of the Earth's mantle and crust. 
Geopotential Research Mission (GRM)

The 1982 CES strategy set forth the primary scientific objectives for the study of solid earth dynamics from space, which included measurement of the Earth's gravitational field from global scales to wavelengths of $200 \mathrm{~km}$ or less. The strategy also recognized the need to measure with increased accuracy the time-dependent deformation in a number of the major worldwide seismic zones and variations in the Earth's rotation rate and polar motion.

The proposed Geopotential Research Mission would contribute to the fulfillment of these objectives by making precise measurements of the Earth's gravitational field. At present, gravity data accurate to $4 \mathrm{mgal}$ with $100-\mathrm{km}$ resolution are publicly available for only 22 percent of the Earth's land area, with geographic and political barriers preventing further acquisition by means of standard ground surveys. Global measurements of the field with an accuracy of 2 to $3 \mathrm{mgal}$ at the Earth's surface, and with spatial resolution of a few hundred kilometers, would contribute significantly to the study of mantle dynamics and tectonics on the continents and the continental margins. Examples include studies of the deep-density structure of the upper mantle, particularly at subduction zones, the thermal structure of the continental lithosphere, the density structure of continental margins, the driving force for continental tectonics, and mantle composition, rheology, ar.d scales of convection. In addition, the measurements would be used for determining the marine geoid with an accuracy necessary for calculating the permanent oceanic circulation from altimeter measurements of sea level made by the TOPEX/Poseidon mission and by other satellites.

One possible mission for measuring the Earth's gravitational field would use a French gravity gradiometer inside a drag-compensated satellite with receivers for tracking the signals from the Global Positioning System satellites. The signals would be used for accurately computing the orbit of the satellite. With launch on a Delta-class vehicle, the total cost of the NASA contribution to the mission would be approximately $\$ 150$ million, which falls within the committee's suggested budgetary limit for Earth Explorers.

\section{Tropical Rainfall Measuring Mission (TRMM)}

In its 1985 strategy this committee stated that the overriding importance, both scientific and societal, of measurements of certain 
elements of the global hydrological cycle and of the causes and signals of climate change makes it essential for such measurements to be included as a part of the overall program for the study of the Earth from space. The committee specifically concluded that accurate measurements of the rates of precipitation, evaporation, and evapotranspiration over the global land and ocean surfaces are objectives of the highest priority for the study of the atmosphere-land-ocean-biota system from space over the next 10 to 15 years.

The Tropical Rainfall Measuring Mission has been roposed for measuring the rainfall in the tropical regions over a period of 3 years to study hydrological processes in the tropics, especially their relationship to the global circulation of the atmosphere and the ocean, and climate variability. The study of trop cal rainfall is of particular importance for several reasons. From an econcmic standpoint, tropical storms driven by intense rainfall cause extensive destruction each year. Tropical rainfall is also the heat engine that drives the global weather, and tropical processes have been linked to global climate change. The extensive surface observations collected by the Tropical Oceans and Global Atmosphere program will be able to complement, but not replace, the satellite measurements, since studies of the rain require accuracies of 0.5 to $1.0 \mathrm{~mm} /$ day made often throughout the full daily cycle.

The proposed satellite mission would fly in an orbital inclination of $30^{\circ}$ to $40^{\circ}$ at an altitude of around $300 \mathrm{~km}$. It would carry a multifrequency, scanning microwave radiometer, a scanning visible and infrared radiometer, and a precipitation radar. The requisite low inclination and orbital elevation preclude acquiring these data from the Eos polar platforms. A joint program between NASA and the National Space Development Agency of Japan is being considered at a cost of approximately $\$ 130$ million to NASA. As in the case of the Geopotential Research Mission, an Earth Explorer program may be the coly way for NASA to implement such a cost-saving, cooperative venture. 


\section{4 \\ Strategy for an Effective Program}

An Earth Explorer program can open new vistas in the earth sciences, encourage innovation, and solve critical scientific problems. Specific missions must be rigorously shaped by the demands and opportunities of high-quality science and must con, lement the Earth Observing System and the Mission to Planet Earth. It is therefore essential that the program follow a comprehensive strategy for accomplishing these goals.

The Committee on Earth Sciences recommends that the new Earth Explorer mission series be funded at a level that would allow the construction of two small missions per year, or one moderate mission every 3 years. Announcements of Opportunity for such missions should be divided according to two separate solicitaxions, one for missions and instruments ccsting less than $\$ 90$ million and one for missions in the $\$ 90$ million to $\$ 150$ million range. The Earth Explorer series should be established as a level-of-effort program similar to the existing Explorer line, but managed entirely by NAS.A's Earth Science and Applications Division. Maintaining independ nt control over the program will help ensure that it remains respon: ve to the needs of the earth sciences community and will prevent the further dilution of an already oversubscribed Explorer program for astronomy and astrophysics, and solar and space physics. The level of funding should be adequate to fly a continuous series of missions at an average rate of approximately one per year. 
In May 1988, NASA issued its first announcement of opportunity (AO) for "small-class Explorer missions" under the existing Explorer program. The AO is intended for the development of spacecraft and instrument payloads that will average approximately $\$ 30$ million or less. This is in contrast to the "Delta-class" missions in the Explorer program that typically cost between $\$ 50$ million and $\$ 150$ million. The committee endorses this apprnach and proposes a similar classification of missions for the Earth Explorer program.

Pr iects that cost under $\$ 30$ million will provide a continuing on unity for quickly implementing flights of srnall free-fyers to .uuct focused scientific investigations, as well as for instruments flown on "missions of opportunity." Such projects are especicuily important for providing training at universities to new generations of scientists and engineers, since universities cannot typically handle larger programs on a comprehensive, end-to-end basis. Finally, the division of the AOs into two separate solicitations will increase programmatic flexibility and decrease response times, while ensuring inat ihe smallest missions are not crowded out by the moderate-size initiatives. (See Appendix B for a table that shows a hypothetical, but representative, distribution of funds and program elements over the first 10 years of the program.)

The traditional strength of the existing NASA Explorer line has been easy, frequent, and inexpensive access to space. The recommendations that follow are designed to return similar opportunities to the earth sciences.

1. The scientific value of Earth Explorer missions must be maximized. The Earth Explorer program will make the maxirnum possible contribution to the earth sciences if the missions are of two varieties: those sharply focused on important, but essentially independent, scientific questions and those designed to complement larger-scale missions or international programs. The independent missions may be aimed at discovery of new phenomena or relationships, or may provide important increments in understanding known phenomena or processes. Consequently, the most important criterion for selecting an Earth Explorer should be that a proposed mission offers the potential for substantial improvement in our understanding of one or more components of the Earth system.

Each Earth Explorer mission therefore must be sharply focused on significant scientific questions and must be justified in its own right. A mission should explore important scientific issues or fill in gaps that may arise in the collection of long-term data sets. The 
program could also provide the collateral benefit of advancing technology development in achieving its objectives. The Earth Explorer series should nct, however, be used for development of instruments for large-scale missions or platforms; such testing should be accomplished by other means, either on aircraft or on the Shuttle, without compromising the scientific integrity of the Earth Explorer series.

2. Programmatic continuity and flexibility mist be maintained. Past experience and the review of potential Earth Explorer missions in Chapter 3 indicate that the earth sciences community can easily identify several outstanding candidates for flight each year for the indefinite future. In order for the recommended program to have a significant impact and to stimulate progress in the earth sciences, it must be initiated with a clear expectation of maintaining uninterrupted continuity.

At the same time, the program must be designed for flexibility, both in choosing the most important scientific questions to address and in allowing for reasonably wide variations in the scale of the missions. Rapid response times are necessary to react in a timely manner to sudden changes in our environmert, or to take advantage of opportunities to collaborate with other agencies or nations. While some missions will cost more than the annual allocation, the number of such large efforts must be sharply limited and balanced by a number of small missions or Earth Explorer payloads attached to other spacecraft as missions of opportunity.

3. Costs must be rigorously controlled in all phases of the program. The key to the success of the Earth Explorer program will be to obtain the maximum scientific value per dollar expended. Toward this end the committee offers the following observations and recommendations:

- Instrumentation: The spiraling costs of instruments for observation from space can be controlled by sharply focusing the scientific objectives, by giving principal investigators the prime responsibility for quality and cost control, and by carefully assessing the tradeoff betueen riliability and multiple copies of instruments. It is essential that the Earth Explorer missions be aimed at only one or twi scientific questions at a time. The temptation to combine as many instruments as possible on a single mission, thereby escalating costs dramatically, can be avoided if frequent opportunities for access to space are available. The earth sciences community needs to fly missions in near.Earth orbit that do not require the compromises in 
orbital parameters, weight, power, and data rates and formats inherent to missions with multiple objectives.

When new instruments must be developed, custom design and engineering can provide enhanced flexibility and reduced mission costs. In contrast, the compromises required to achieve a welldesigned instrument with standard parts often demand engineering and development costs that exceed those of custom design and entail undesirable constraints on power, weight, and capability.

For most missions, the principal investigators should be given specific iesponsibility for quality control, even if the instrument is manufactured by a contractor. The quality of the instrument should be created in the design, rather than be a result of a highly bureaucratic, expensive quality control process.

Finally, the issue of reliability versus multiple copies should be thoroughly $r$ examined to determine the basic policies of an Earth Explorer program. The committee believes that smaller missions will lead to considerably cheaper instruments because achieving an acceptable proivability of success with two or more missions should be easier than atcaining a vanishingly small probability of failure in a single attempt.

- Spacecraft and Launch Vehicles: In contrast to the case for instruments, the committee recommends the use of standard satellite buses and launch vehicles whenever this is both scientifically and ecunomically advantageous. These elements can integrate easily with simple instrument systems, and a multiple production run allows a contractor to achieve important economies of scale in production. Small spacecraft concepts are currently being studied by the Defense Advanced Research Programs Agency, and a number of small (Scoutclass) and medium size (Delta-class) expendable launch vehicles are being developed by the private sector. With the increasing emphasis on commercial participation in the space program, both spacecraft and launch vehicles are likely to become more flexible, more capable, and more competitive in price, thus enhancing the accomplishments possible with the Earth Explorer program.

4. The data transmission and processing requirements for many Earth Explorers are likely to be relatively modest, given the emphasis on strongly focused missions. Reductions in cost often will be realized by using standard telemetry equipment and relatively simple data acquisition systems, perhaps those operated by other federal agencies or by the principal investigator. Complicated arrangements within 
the government or with commercial satellite manufacturers would increase hardware and project management cosis.

The committee expects that most of the basic processing of data from the rnajority of Earth Explorer missions can be performed by the principal investigator on dedicated computational equipment. Strict schedules and reliability requirements must be met, and the data should be made available as quickly as possible to scientific archives or to open networks in scientific fo:mats.

Furthermore, the Earth Explorer series offers the opportunity for the NASA Earth Sciences and Applications Division to gain valuable experience with distributed data systems. Earth Explorer data released by the principal investigator should flow to active data bases, perhaps to one of the pilot data systems, and then to the community over networks operated by NASA, other federal agencies, and international organizations. Optimum use of the Earth Explorer observations will surely require comparison with data from other missions and from operational data sources. As a result, careful planning and experimentation with the integration over networks of data from diverse sources will be essential. These efforts should be approached with the idea that they are important in preparing for the data management challenges of earth system science in the Eos era, and thus resources should be apportioned accordingly.

5. A significant fraction of the total costs of each mission should be allocated to data analyais, interpretation, and related theoretical or modeling work. Because the scientific objectives for any mission are achieved only after the data have been distributed and thoroughly analyzed, adequaie funding for this purpose is fundamental to the mission's success. NASA will need to augment its annual mission operations and data anaiysis budget by an amount sufficient to conduct all such activities associated with each Earth Explorer mission.

6. A basic goal of the Earth Explorer program must be to speed up the conversiun of concepts into satellite missions and of raw data into scientific results. The time scales of the program must be designed to attract leading scientists and talented students, and to avoid the mounting costs of protracted space projects. Therefore it is important that the smallest missions be launched within 2 to 3 years of acceptance for engineering design, and moderate missions be launched within 3 to 4 years. Meeting such a schedule requires that the instrument systems and spacecraft be kept relatively simple and within the adopted cost limits.

7. The Explorer program must develop a selection process that 
encourages the best ideas and does not require inordinate investments in engineering design during the initial proposal phase. Thus inis committee argues, as did the Committee on Solar and Space Physics in its 1.984 strategy, that the selection process should proceed in two phases. In the first phase, proposals would be requested that emphasize the scientific issues and the instrument concepts, with only a limited discussion of engineering issues. In the second phase, only the most promising corcepts would be chosen for further development and preliminary instrument design in order to continue in the selection process. This approach would minimize the total community investment in preparing proposals, and it would attract scientists with good ideas but limited resources to compete in the preliminary phase of Earth Explorer selection. Because scientific advances and emerging problems cannot be foreseen a decade in advance, the se' ${ }^{1}$ ction process for new missions and instruments should be designed to permit flexibility on the scale of 2 to 3 years. The same process would apply to both the small (less than $\$ 30$ million) and the moderate ( $\$ 30$ million to $\$ 150$ million) mission proposais. In any event, overselection of missions and ins ${ }^{+}$ruments should be assiduously avoided.

8. Interagency and international collaboration musi be optimized. Collaboration with other agencies and nations fosters the development of a stronger space science program at reduced cost to NASA. It is ayiomatic therefore that every opportunity for cooperation in utilizing and financing Farth Explorer missions should be considered.

The individual missions supported by the Earth Explorer nrograin will involve different degrees of technology development and financial commitment. The National Science Foundation (NSF, the National Oceanic and Atmospheric Administration (NOAA), the United States Geological Survey (USGS), and the Department of Defense (DOD) have various interests in the earth sciences and in space observations that are compatible with those of NASA. The norm should be close cooperation in all areas in which agency interests converge.

Many missions will also stimulate and benefit from internation al cooperation. Through direct collaboration in joint missions, projects otherwise too ambitious for the Earth Explorer line can be accommodater. Examples of cooperative projects under active negotiation include plans to fly a scatterometer ant the trcpical rainfall measuring system on Japanese spacecraft and the proposal between NASA 
and the French Centre Nationale des Etudes Spatiales (CNES) to fly a magnetic observer.

The Earth observation missions of other nations will complement and supplement the data obtained from NASA and NOAA satellites. All nations involved in the exploration of the Earth from space will benefit by combining their data and learning to develop interactive data systems of international scope. Surface data from other nations also will be required. For inst: nce, data from the international network of surface magnetic observatories auc necessary for separating spatial magnetic variations observed by a satellite from magnetic storms.

In addition, there are opportunities to share the use of ground facilities. For example, the operation of equatorial three-component magnetic obse:vatories by the USGS is an essential complement to satellite observations of magnetic field intensity. Air Force ground stations might be used to collect data from satellites, thus decressing costs of onboard data hardware. Surface weather observations or profile data from NOAA satellites will often be needed in analyzing atmospheric or surface observations or in compensating for atmospheric effects on electromagnetic transmission.

Finally, as discussed in the previous chapters, the Earth Explorer program is essential for completing key measurements that will be made through international research programs in the earth sciences, such as the International Geosphere Biosphere Program-A Study of Global Change (IGBP) and the World Climate Research Program. The Earth Explorer missions will benefit from the broad expertise available in the international scientific community, and the missions will make greater contributions if they answer scientific questions of vital international interest. Many of the mechanisms for facilitating interagency and international cooperation are in place and are being used with incieasing effectiveness.

In conclusion, the committee believes that the proposed Earth Explorer program provides a substantial opportunity for progress in the earth sciences, both through independent missions and through missions designed to complement the large-scale platforms and international programs that represent important national commitments. The strategy presented in this report is intended to help ensure the success of the Earth Explorer program as a vital stimulant to the study of our planet. 
Appendixes 


\section{Appendix A References}

\section{SPACE SCIENCE BOARD REPORTS}

A Strategy for Earth Science from Space in the 1980's-Part I: Solid Earth and Oceans, CES (1982)

A Strategy for Furth Science from Space in the 1980's and 1990'sPart II: Atmosphere and Interactions with the Solid Earth, Oceans, and Biota, CES (1985)

Remote Sensing of the Biosphere, Committee on Planetary Biology (1986)

A Strategy for the Explorer Program for Solar and Space Physics, Committee on Solar and Space Physics (1984)

The Explorer Program for Astronomy and Astrophysics, Committee on Space Astronomy and Astrophysics (1986)

Data Management and Computation-Volume I: Issues and Recommendations, Committee on Data Management and Computation (1982)

Issues and Recommendaiions Associated with Distributed Computation and Data Management Systems for the Space Sciences, Committee on Datis Management and Computation (1986)

Preceding page blank 
Space Science in the Twenty-first Century: Mission to Planet Earth, Task Grrup on Earth Sciences (1988)

\section{OTHER NATIONAL RESEARCH COUNCIL REPORTS}

Toward an International Geosphere-Biosphere Program: A Study of Global Change, Netional Research Council workshop (1983)

Remote Sensing of the Earth from Space: A Program in Crisis, Space Applications Board (1985)

Global Change in the Geosphere-Biosphere: Initial Priorities for an IGBP, U.S. Committee for an International Geosphere-Biosphere
Program (1986) Current Issues in Atmospheric Change, Board on Atmospheric Sci-
ences and Climate (1987)

\section{NASA REPORTS}

Earth Observing System, Volume I, Science and Mission Requirements Working Group (1984)

The Crisis in the Space and Earth Sciences, Space and Earth Sciences Advisory Committee (1986)

NASA Earth Science and Applications Division: The Program and Plans for FY 1987-1988-1989, NASA (1987)

Linking Remote-Sensing Technology and Global Needs: A Strategic Vision, Applications Working Group (1987)

Leadership and America's Future in Space, NASA (1987)

System Concept for Wide-Field-of-View Observations of Ocean Phenomena from Space, NASA/NOAA/EOSAT (1987)

Earth System Science: A Program for Global Change, Earth System Science Committee (1988) Announcement of Opportunity: Small-Class Explorer Mission,
NASA (1988)

\section{OTHER REPORTS}

The OSS Explorer Program: A Status Review, Volumes I and II, by R. Teeter and M. Kuhner, Battelle (1980) 
Observing Systems for Clobal Change, Committee on Space Research/International Council of Scientific Unions (1986)

The Atmosplueric Sciences: A Vision for 1989-1994, National Science Foundation-UCAR Long Range Planning Committee (1987)

Proceedings on the First Annual USU Conference on Small Satellites, Utah State University (1987)

\section{ARTICLES}

Antarctic Ozone Hole Special Issue, 1987: Geophys. Res. Lett., 13(12), 1191-1362.

Barkstrom, B.R., 1984: The Earth Radiation Budget Experiment (EREE), Bull. Amer. Meteorol. Soc., 65, 1170-1185.

Bowman, K.P., and A.J. Krueger, 1985: A global climatology of total ozone from the Nimbus 7 total ozone mapping spectrometer, J. Geophys. Res., 90, 7967-7976.

ERBE Science Team, 1986: First data from the Earth Radiation Budget Experiment (ERBE), Bull. Amer. Meteorol. Soc., 67, 818824.

ERBE Special Issue, 1986: Rev. Geophys. Space Phys., 24(2), 350468.

GEOS-3, Special issue, 1979: J. Geophys. Res., 84(B8).

Horan, J.J., 1978: Nimbus-The Vanguard of Remote Sensing, IEEE Spectrum 15(9), 36-43.

LAGEOS, Special issue, 1985: J. Geophys. Res., 90(B11).

Origin and Evolution of Seamounts, Special issue, 1984: J. Geophys. Res., 89(B13).

Reichle, H.G., et al. 1986: J. Geophys. Res., 91(C9).

Schoeberl, M.R., A.J. Krueger, and P.A. Newman, 1986: The morphology of the Antarctic total ozone as seen by TOMS, Geophys. Res. Letters 13, 1217.

Seasat I, Special issue, 1982: J. Geophys. Res., 87(C5).

Seasat, II, Special issue, 1983: J. Geophys. Res., 88(C3). 
Stolarski, R.S., A.J. Krueger, M.R. Schoeberl, R.D. McPeters, P.A. Newman, and J.C. Alpert, 1986: Nimbus 7 SBUV/TOMS measurements of the springtime Antarctic ozone hole, Nature, 322, 808-811.

\section{PRESENTATIONS}

October 5-7, 1987, at the National Academy of Sciences, Washington, D.C.

Shelby Tilford, NASA

Dixon Butler, NASA

John Theon, NASA

Edward Flinn, NASA

Robert Murphy, NASA

W. Stanley Wilson, NASA

James Yoder, NASA

James Richman, NASA

Robert Corell, NSF
Thomas Pyke, NOAA

Harold Yates, NOAA

Jeffrey Maclure, NOAA

Lisle Rose, State Department

William Smith, U.S. Congress

Peter Perkins, U.S. Congress

Martin Kress, U.S. Congress

Jack Fellows, OMB

February 1-2, 1988, at the Jet Propulsion Laboratory, Pasadena, California

Moustafa Chahine, JPL

Kerry Nock, JPL

Lisle Rose, State Department

April 14-15, 1988, at the National Academy of Sciences, Washington, D.C.

Shelby Tilford, NASA

S. Ichtiaque Rasool, NASA

Edward Flinn, NASA

Additional information was provided by the following individuals: Waner Gruhl, NASA; George Parks, NASA; Ronald Konkel, NASA; Robert Langel, NASA/Goddard; Gilbert Ousley, NASA/Goddard; William Hibbard, NASA/Goddard; Wayne Esaias, NASA/Goddard; Chet Koblinsky, NASA/Goddard; Arlin Krueger, NASA/Goddard; Steven Paddack, NASA/Goddard; Henry Reichle, NASA/Langley; Ed Harrison, NASA/Langley; Matthew Willard, EOSAT; and Terri Gregory, University of Wisconsin. 


\section{Appendix B \\ Representative Earth Explorer Program}

The following tables provide a hypothetical example of the distribution of funds and program elements over the first 10 years of an Earth Explorer program funjed at a level of $\$ 75 \mathrm{M}$ per year (in 1988 dollars). Spacecraft and instrument design costs for the program are estimated at 5 to 10 percent of the total hardware costs. Mission operations and data analysis (MO\&DA) costs are not included in the table as part of the budget envelope. The committee expects adequate resources to be budgeted from the regular MO\&DA budget of the Earth Science and Applications Division. Finally, launch costs also are not included as part of the proposed budget. 
TABLE B.1 Small Missions/Instruments for the First Ten Years of a Representative Earth Explorer Program

\begin{tabular}{|c|c|c|c|c|c|c|c|c|}
\hline & A1 & A2 & A3 & A4 & A5 & A6 & A7 & A8 \\
\hline 1990 & $\$ 8(C)$ & & & & & & & \\
\hline 1991 & & $\$ 3(D)$ & & & & & & \\
\hline 1992 & & $\$ 12(\mathrm{C})$ & $\$ 3(D)$ & & & & & \\
\hline 1993 & & $\$ 9$ (C) & $\$ 3(C)$ & $\$ 2$ (D) & & & & \\
\hline 1994 & & & $\$ 7(C)$ & $\$ 18(\mathrm{C})$ & $\$ 2(D)$ & & & \\
\hline 1995 & & & & $\$ 10(\mathrm{C})$ & $\$ 19(C)$ & $\$ 1(D)$ & & \\
\hline 1996 & & & & & $\$ 9(\mathrm{C})$ & $\$ 8(C)$ & & \\
\hline 1997 & & & & & & & $\$ 2$ (D) & \\
\hline 1908 & & & & & & & $\$ 16(C)$ & $\$ 3(D)$ \\
\hline 1999 & & & & & & & $\$ 8(C)$ & $\$ 18(C)$ \\
\hline
\end{tabular}

NOTE: All figures are in \$million and in 1987 dollars. (D) indicates design (phases $A$ and $B$ ), and (C) indicates construction (phases $C$ and D). 
TABLE B.2 Moderate Missions for the First Ten Years of a Representative Earth Explorer Program

\begin{tabular}{|c|c|c|c|c|c|c|c|}
\hline & B1 & B2 & B3 & B4 & B5 & $\mathrm{B} 6$ & $\begin{array}{l}\text { ANNUAL } \\
\text { BUDGET }\end{array}$ \\
\hline 1990 & $\begin{array}{l}{[\$ 5(D)]} \\
\$ 22(C)\end{array}$ & & & & & & $\$ 30 \mathrm{M}$ \\
\hline 1991 & $\$ 47(C)$ & $\$ 5(D)$ & & & & & $\$ 55 \mathrm{M}$ \\
\hline 1992 & $\$ 25(\mathrm{C})$ & $\$ 35(C)$ & & & & & $\$ 75 \mathrm{M}$ \\
\hline 1993 & & $\$ 52(\mathrm{C})$ & $\$ 1(D)$ & & & & $\$ 75 \mathrm{M}$ \\
\hline 1994 & & $\$ 36(C)$ & $\$ 12(\mathrm{C})$ & & & & $\$ 75 \mathrm{M}$ \\
\hline 1995 & & & $\$ 39(C)$ & $\$ 6(D)$ & & & $\$ 75 \mathrm{M}$ \\
\hline 1996 & & & $\$ 10(C)$ & $\$ 45(C)$ & $\$ 3(D)$ & & $\$ 7 E M$ \\
\hline 1997 & & & & $\$ 46(C)$ & $\$ 27(C)$ & & $\$ 75 \mathrm{M}$ \\
\hline 1998 & & & & $\$ 28(C)$ & $\$ 25(C)$ & $\$ 3(D)$ & $\$ 75 \mathrm{M}$ \\
\hline 1999 & & & & & $\$ 15(\mathrm{C})$ & $\$ 36(C)$ & $\$ 75 \mathrm{M}$ \\
\hline
\end{tabular}

NOTE: All figures are in \$million and in 1987 dollars. (D) indicates design (phases $A$ and $B$ ), and (C) indicates construction (phases $C$ and D). 